\title{
ECOSSISTEMA ÁGIL DE INOVAÇÃO NO SETOR AGROPECUÁRIO BRASILEIRO
}

Silvia Ronsom José Eustáquio Ribeiro Vieira Filho Daniel Capaldo Amaral
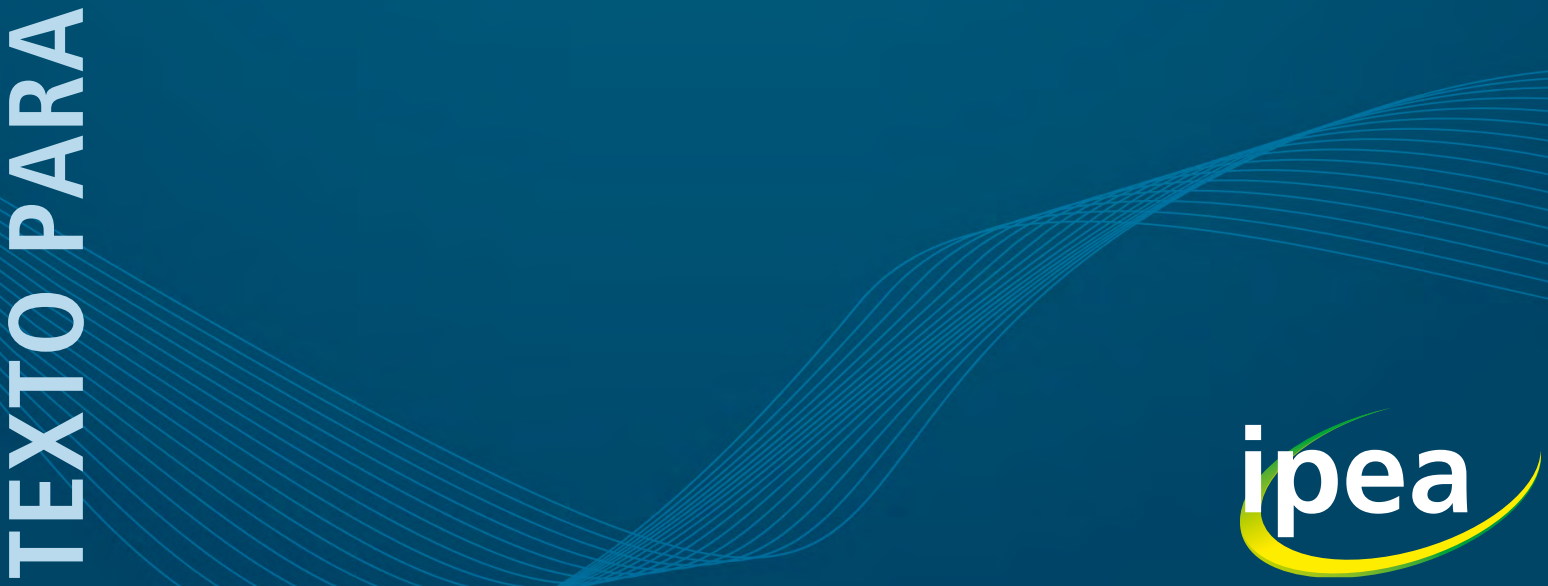



\section{TEXTO PARA DISCUSSÃO}

Brasília, março de 2021

\section{ECOSSISTEMA ÁGIL DE INOVAÇÃO NO SETOR AGROPECUÁRIO BRASILEIRO}

Silvia Ronsom ${ }^{2}$

José Eustáquio Ribeiro Vieira Filho ${ }^{3}$

Daniel Capaldo Amaral ${ }^{4}$

1. A equipe de pesquisa agradece ao Ministério da Agricultura, Pecuária e Abastecimento (Mapa), ao Ipea, à Empresa Brasileira de Pesquisa Agrícola (Embrapa) e à Universidade de São Paulo (USP), por viabilizar a estruturação e o desenvolvimento do referido estudo.

2. Pesquisadora do Núcleo de Estudos de Economia Agrícola (ne2agro Ipea-Mapa), na Diretoria de Estudos e Políticas Regionais, Urbanas e Ambientais (Dirur) do Ipea. E-mail: <sronsom@gmail.com>.

3. Técnico de planejamento e pesquisa na Dirur/lpea; diretor de programa da Secretaria Executiva do Mapa; e professor do Programa de Pós-Graduação em Agronegócio da Universidade de Brasília (Propaga/UnB) e do Programa de Pós-Graduação em Economia Aplicada da Universidade Federal de Viçosa (PPGEA/UFV). E-mail: <jose.vieira@ipea.gov.br>

4. Professor associado no Departamento de Engenharia de Produção da Escola de Engenharia de São Carlos, na USP. E-mail: <amaral@sc.usp.br>. 


\section{Governo Federal \\ Ministério da Economia \\ Ministro Paulo Guedes}

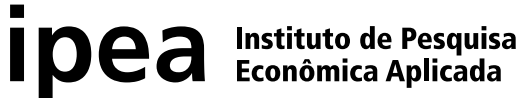

Fundação pública vinculada ao Ministério da Economia, o Ipea fornece suporte técnico e institucional às ações governamentais - possibilitando a formulação de inúmeras políticas públicas e programas de desenvolvimento brasileiros - e disponibiliza, para a sociedade, pesquisas e estudos realizados por seus técnicos.

\section{Presidente}

Carlos von Doellinger

Diretor de Desenvolvimento Institucional Manoel Rodrigues Junior

Diretora de Estudos e Políticas do Estado, das Instituições e da Democracia

Flávia de Holanda Schmidt

\section{Diretor de Estudos e Políticas \\ Macroeconômicas \\ José Ronaldo de Castro Souza Júnior}

Diretor de Estudos e Políticas Regionais, Urbanas e Ambientais

Nilo Luiz Saccaro Júnior

Diretor de Estudos e Políticas Setoriais de Inovação e Infraestrutura

André Tortato Rauen

\section{Diretora de Estudos e Políticas Sociais}

Lenita Maria Turchi

Diretor de Estudos e Relações Econômicas

e Políticas Internacionais

Ivan Tiago Machado Oliveira

\footnotetext{
Assessor-chefe de Imprensa

e Comunicação (substituto)

João Cláudio Garcia Rodrigues Lima

Ouvidoria: http://www.ipea.gov.br/ouvidoria

URL: http://www.ipea.gov.br
}

\section{Texto para Discussão}

Publicação seriada que divulga resultados de estudos e pesquisas em desenvolvimento pelo Ipea com o objetivo de fomentar o debate e oferecer subsídios à formulação e avaliação de políticas públicas.

(C) Instituto de Pesquisa Econômica Aplicada - ipea 2021

Texto para discussão / Instituto de Pesquisa Econômica Aplicada.- Brasília : Rio de Janeiro : Ipea , 1990-

ISSN 1415-4765

1.Brasil. 2.Aspectos Econômicos. 3.Aspectos Sociais. I. Instituto de Pesquisa Econômica Aplicada.

CDD 330.908

As publicações do Ipea estão disponíveis para download gratuito nos formatos PDF (todas) e EPUB (livros e periódicos).

Acesse: http://www.ipea.gov.br/portal/publicacoes

As opiniões emitidas nesta publicação são de exclusiva e inteira responsabilidade dos autores, não exprimindo, necessariamente, o ponto de vista do Instituto de Pesquisa Econômica Aplicada ou do Ministério da Economia.

É permitida a reprodução deste texto e dos dados nele contidos, desde que citada a fonte. Reproduções para fins comerciais são proibidas. 


\section{SUMÁRIO}

SINOPSE

ABSTRACT

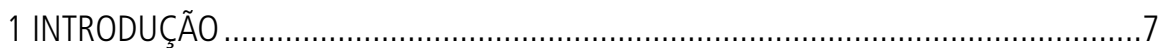

2 MÉTODO

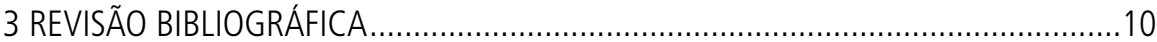

4 ESTRATÉGIAS E PRÁTICAS DIRECIONADAS PARA AGILIDADE NA EMBRAPA ..........26

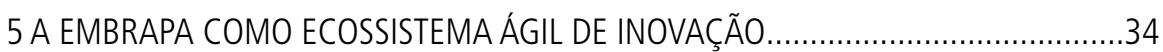

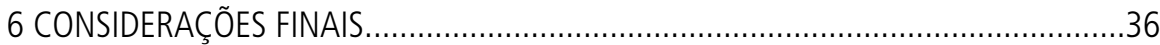

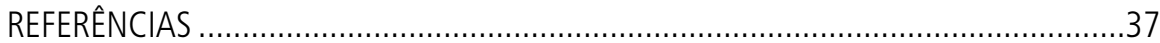





\section{SINOPSE}

A agricultura brasileira é um caso de sucesso em termos de inovação tecnológica, explicado, entre outros fatores, pela dinâmica construída entre organizaçóes de pesquisa e atores do agronegócio, que caracterizam um ecossistema de inovaçáo. O conceito de "agilidade" é central na competitividade e na esfera do gerenciamento de tais ecossistemas. A agilidade tem sido discutida como habilidade de adaptação para melhoria das capacidades de inovação de organizaçóes em ambientes marcados por alta complexidade. Busca-se apresentar as definiçóes e os conceitos de ecossistema de inovação e agilidade, bem como sua relação com os ambientes institucionais. A análise auxilia a compreensão dessa abordagem para a construção de políticas públicas e diretrizes para a gestão da inovação no setor agropecuário. Por ser elo importante no ecossistema de inovaçáo no agronegócio, a Empresa Brasileira de Pesquisa Agropecuária (Embrapa) será objeto de estudo. Resultados de avaliação experimental e exploratória são apresentados, demonstrando haver exemplos na busca de agilidade. Espera-se compreender melhor os desafios de repensar os processos de inovação no agronegócio brasileiro.

Palavras-chave: agricultura; pesquisa; ecossistemas de inovação; agilidade; Embrapa.

\section{ABSTRACT}

Brazilian agriculture is a technological innovation success case, explained, among other factors, by the dynamics built between research organizations and agribusiness actors that characterize an innovation ecosystem. The concept of "agility" is central to the competitiveness and management of such ecosystems. Agility has been discussed as adaptation ability to improve the innovation capacities of organizations in environments with high complexity. This work seeks to present the definitions and concepts of the innovation ecosystem, agility and its relationship with institutional environments. The analysis helps to understand this approach for the construction of public policies and guidelines for the management of innovation in the agricultural sector. Considered an important link within the innovation ecosystem in agribusiness, the Brazilian Agricultural Research Corporation (Embrapa) will be the focus of study. Results of experimental and exploratory evaluation are presented, showing the existence of examples towards agility. It is expected to better understand the challenges of rethinking innovation processes in Brazilian agribusiness.

Keywords: Agriculture, Research, Ecosystem of Innovation, Agility, Embrapa. 



\section{INTRODUÇÃO}

A complexidade dos cenários econômico e social, a aceleração das mudanças tecnológicas e a comunicação instantânea têm exigido capacidade de adaptação de organizações dos setores público e privado (Sull, 2009; OECD, 2015). A crise sanitária gerada pelo coronavírus intensificou ainda mais o caráter de urgência. Sem precedentes nas últimas décadas, trouxe implicaçôes econômicas, políticas, sociais e morais, que poderão durar por tempo indeterminado e gerar profundas mudanças (Denning, 2020).

A agricultura brasileira seguiu em expansão e colheu a maior safra de grãos, com cerca de 258 milhóes de toneladas em 2020, apesar da crise e do período de incertezas (Vieira Filho, 2020; Brasil, 2020). O país é grande produtor agropecuário e será agente central na oferta mundial de alimentos, com a Rússia, a Índia, a China, a Europa Ocidental e os Estados Unidos (Crestana e Fragalle, 2012; Vieira Filho e Fishlow, 2017; OCDE e FAO, 2018). Contudo, para alimentar cerca de 8,6 bilhóes de pessoas até 2030, há inúmeras questóes desafiadoras, entre as quais se destaca a ineficiência do sistema de produção alimentar (ONU, 2015; 2017; Caisan, 2018; Zaro, 2018). Será preciso desenvolver políticas públicas que possam melhorar o ambiente institucional dos países produtores, com o objetivo de atender à crescente demanda por alimentos.

O Plano de Estado 2018-2030 (CNA e Conselho do Agro, 2018) enfatiza que, sem uma visão pragmática, o país seria empurrado para a margem do progresso tecnológico e apresenta diversos eixos de desenvolvimento para orientar açóes de ciência e tecnologia $(C \& T)$. Diretrizes são apresentadas, tais como o aperfeiçoamento das ferramentas de gestão de órgáos fundamentais para a inovação tecnológica; o desenvolvimento da pesquisa agropecuária focada na geração de conhecimentos e tecnologias de impacto; a diminuiçáo da burocracia e das atividades-meio; o resgate da autonomia dos centros de pesquisa; e a flexibilização de operaçóes e convênios com instituiçốes de ciência, tecnologia e inovação (CT\&I) no Brasil e no mundo (op. cit., p. 94). Este estudo busca discutir a inovaçáo, especificamente no contexto do setor agropecuário brasileiro.

Melhorias institucionais, portanto, são requeridas. Esse debate não é novo. Essas questôes estão presentes na literatura e no ambiente organizacional. O conceito de ecossistemas de inovação, no entanto, necessita de melhor compreensão nas economias em desenvolvimento, segundo Hoffecker (2019). A autorrenovação seria premissa vital para esses ecossistemas (Moore, 1993; Rubens et al., 2011; Nambisan e Baron, 2013; Iansiti e Euchner, 2018), e a inovação em gestão, discutida em trabalhos como Birkinshaw, Hamel e Mol (2008), Alange, Jacobsson e Jarnehammar (1998) e Guillén (1994), é vista como central nessa discussão. 
É preciso observar uma questáo-chave (a mudança de paradigma na pesquisa agrícola). Douthwaite e Hoffecker (2017) compararam a abordagem linear de transferência de tecnologia (TT) da década de 1990 com outra que se destacou por ser mais sensível às complexidades contemporâneas. $\mathrm{O}$ estudo analisou o papel dos agricultores, da função dos cientistas e da dinâmica do sistema agropecuário. A pesquisa preestabelecida foi movida por uma agenda de conhecimento aberto, que impulsionou a construção de relacionamentos e confiança das partes interessadas. Apesar da ampla literatura sobre abordagens mais dinâmicas, flexíveis e complexas (Campbell e Sayer, 2003; Ojha e Hall, 2013; Ayele et al., 2012; Wigboldus et al., 2016; Schut et al., 2016), existem poucos exemplos concretos que consideram essas características ou que forneçam orientação prática para seu desenvolvimento.

Uma abordagem de gestáo inovadora, que se destaca em ambientes complexos, é a gestão ágil e o emprego do conceito de agilidade. A Organização para a Cooperação e Desenvolvimento Econômico - OCDE (OECD, 2015), na esfera da governança pública, aborda a agilidade estratégica como fator fundamental para adaptação diante de desafios e oportunidades do cenário socioeconômico. A mençáo ao termo agilidade tem sido frequente no debate macroeconômico de inovação.

Vieira Filho, Gasques e Ronsom (2020) apresentaram um panorama sobre a inovação e a expansão agropecuária brasileira, considerando dados históricos de ediçóes do Censo Agropecuário do Instituto Brasileiro de Geografia e Estatística (IBGE). A busca da agilidade como potencial caminho para mudanças institucionais foi destacada. No entanto, seria necessário desenvolver de forma mais detalhada a questáo. Necessita-se, entáo, de estudos que demonstrem os potenciais caminhos para desenvolvimento de agilidade para ecossistemas de inovação na agricultura.

A Embrapa, como um dos atores principais da pesquisa agrícola brasileira, será foco de análise. Para facilitar a investigação do tema, as seguintes perguntas de pesquisa são apresentadas:

- o que seria agilidade para ecossistemas de inovação como a Embrapa?;

- quais estratégias ampliariam a agilidade dos seus processos?;

- quais práticas ágeis poderiam ser utilizadas nas unidades descentralizadas de pesquisa?; e

- quais seriam as principais limitaçóes e desafios para seu desenvolvimento?

Em busca de analisar o desafio técnico-científico que emerge dessa discussão, consideram-se os seguintes objetivos do estudo: discutir ecossistemas de inovação, inovação 
em gestão e implicaçôes da pesquisa agrícola com base na teoria de agilidade; descrever exemplos de estratégias e práticas ágeis a serem identificadas na Embrapa; e verificar o potencial da teoria na compreensão dos desafios e transformaçóes do ecossistema de inovação dessa instituição.

O estudo está dividido em seis seções, incluindo-se esta breve introdução. A seção 2 apresenta o método de análise. A seção 3 realiza a revisão de literatura, que busca contextualizar a expansão da agricultura brasileira e a abordagem ágil como alternativa de inovação em gestão. A seção 4 mostra um conjunto de potenciais estratégias e práticas de agilidade identificado na Embrapa. A seção 5 faz uma síntese sobre o potencial da teoria de agilidade na compreensão dos desafios da questão institucional do setor agropecuário brasileiro. Por fim, seguem as consideraçóes finais.

\section{MÉTODO}

Este trabalho faz parte de um programa de pesquisa para o desenvolvimento de instrumentos mais dinâmicos para gestão dos ecossistemas de inovação da agricultura, apoiado pelo Ipea e pelo Mapa, por meio do ne2agro Ipea-Mapa.

O estudo procura avaliar e aprofundar no tema da mudança institucional relacionada com agilidade, especificamente no setor agropecuário brasileiro. Verifica-se a possibilidade de observar aspectos de agilidade na prática de organizaçóes do ecossistema de inovação da agricultura. Embora este texto foque em questôes de agilidade e inovação na agricultura, a linha de pesquisa é extensa e será abordada em cinco fases, descritas a seguir.

1) Análise documental: tem o objetivo de mapear em grandes linhas a visão do país em relação a expansão da agricultura ante os desafios mundiais. Citam-se, como exemplos de estudos do Estado voltados à discussáo de melhoria institucional em termos de tecnologia e inovação agrícola, as políticas de inovação da Embrapa e os principais relatórios institucionais que citam o tema de agilidade.

2) Revisão da literatura: ${ }^{1}$ busca-se identificar os principais conceitos e características de agilidade disponíveis na literatura para o domínio da pesquisa, que são os ecossistemas de inovação e a pesquisa agricola. As seguintes atividades foram realizadas:

1. Procedimento baseado em Conforto, Amaral e Silva (2011). 
estudos de fontes primárias e identificação de principais construtos; identificação de atores do ecossistema; busca nas bases científicas (Web of Science e Scopus); seleção de artigos; e leituras e análises de conteúdo. Tal análise foi realizada com base em frames semânticos² e por codificação aberta de categorias (Elo e Kyngas, 2007).

3) Objeto de estudo: análise teórica sobre a evolução da dinâmica de inovação da Embrapa à luz do referencial teórico, com a indicação de possíveis estratégicas e ações para a organização.

4) Entrevistas com especialistas: tiveram caráter experimental e exploratório (Gil, 1999), com o objetivo de verificar se as características identificadas na literatura seriam encontradas na Embrapa e em suas unidades. Não foi objetivo dessas entrevistas identificar correlaçóes entre variáveis.

5) Planejamento das entrevistas: i) seleção de especialistas (cinco entrevistados), sendo estes ocupantes de cargos de diretoria ou de assessoria da Embrapa e de unidades descentralizadas; ii) discussão e obtenção de informaçóes e documentos publicados sobre o tema; e iii) consolidação e análise de dados.

\section{REVISÃO BIBLIOGRÁFICA}

\subsection{A expansão da agricultura brasileira e a preparação institucional e tecnológica para inovar}

Estimativas indicam que o planeta terá cerca de 8,6 bilhôes de pessoas em 2030 (ONU, 2017). Evidências sugerem que a falta de alimentos não seja um problema global, e sim a ineficiência do sistema alimentar. Haveria falhas em todo o processo de produção e consumo. Cerca de um terço dos alimentos produzidos são perdidos entre a fazenda e a mesa, enquanto são armazenados, transportados, processados, embalados, vendidos e preparados (Caisan, 2018; Zaro, 2018; Peixoto e Pinto, 2016). A solução desses problemas deve ser o foco das políticas e da organização da cadeia de produção dos países.

Para a expansão da oferta de alimentos no mundo, o Brasil é destacado como um dos países que exercerá papel fundamental, com a Rússia, a Índia, a China, a Europa Ocidental e os Estados Unidos (OCDE-FAO, 2018). As exportaçóes de carne da América Latina deverão crescer em torno de 31\% em relação ao período-base 2015-2017. Segundo o relatório, cerca de $70 \%$ desse crescimento será baseado no desempenho da economia

2. Elementos de análise semântica utilizados por Conforto et al. (2016).

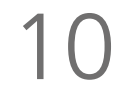


brasileira. Além disso, no Brasil e no Chile, espera-se um aumento de $43 \%$ da produção aquícola. Com o emprego das tecnologias que poupam os fatores escassos, a oferta de grãos deve-se expandir, notadamente soja e milho, assim como a produção de etanol.

Desde a década de 1970, o país tornou-se uma potência agropecuária (agrícola, pecuária, florestal e agroenergética) e ambiental (Crestana e Fragalle, 2012). A trajetória de sucesso da agricultura brasileira nos últimos cinquenta anos é documentada por Vieira Filho e Fishlow (2017). De acordo com Gasques (2017), a produtividade total dos fatores (PTF) atingiu a marca de aproximados 4,3\% (taxa de crescimento médio anual) em 2017, colocando o Brasil em destaque em relação a outros países, tais como: Argentina (2,7\%); Chile (3,1\%); Estados Unidos (1,9\%); e China (3,3\%).

O investimento em pesquisa e tecnologia foi importante para contribuir com essa realidade. A tecnologia é o fator que mais influenciou no aumento da produção agrícola (Alves, Silva e Souza e Rocha, 2012; Vieira Filho, Gasques e Ronsom, 2020). De um lado, a inovação tecnológica aumenta a produtividade e, consequentemente, a renda bruta, enquanto, de outro, auxilia na redução do custo de produção agrícola (Vieira Filho e Silveira, 2011; Alves et al., 2019). De acordo com Alves et al. (2019), o governo e a iniciativa particular precisam reunir esforços para viabilizar a geraçáo e a difusão de tecnologia de forma continuada.

Além do investimento em tecnologia, é importante que o país possa aproveitar as sinergias institucionais e técnicas para inovar, buscando preparar-se para os desafios contemporâneos. Para Crestana, Contini e Rodrigues (2018), o atendimento aos desafios do crescimento passará pelo pensar em uma nova agricultura, que dará início a um novo ciclo de produçáo e desenvolvimento, apoiada no conceito da agricultura $4.0 \mathrm{ou}$ digital - também chamada "inteligente" - e das tecnologias convergentes. O trabalho institucional deve ser criativo, com vistas a ganhar maior agilidade e flexibilidade nas parcerias e na busca de recursos no âmbito nacional e no exterior. Seria no contexto da complexidade de problemas e soluçóes que o Brasil se destacaria como provedor mundial de segurança alimentar.

Os esforços públicos caminham nesse sentido. Ciente da complexidade, apresentada por meio do Plano de Estado 2018-2030 (CNA e Conselho do Agro, 2018, p. 91), diversos eixos de desenvolvimento foram traçados. Pretende-se discutir o tema da inovação, mais especificamente no setor agropecuário brasileiro, que se destaca pela prosperidade econômica da agricultura, da pecuária, da agroindústria e da capacidade acadêmica e inovadora do setor. Segundo o plano, a promoçâo da competitividade da 
agropecuária e da agroindústria brasileira visa fomentar a criação de empregos, inclusive os especializados, e alavancar o crescimento econômico. No ambiente globalizado, há a competição entre os Estados, principalmente os mais influentes, que concentram os esforços e os investimentos nas pesquisas científicas destinadas à implementação de novas técnicas. A importância da modernização das instituiçóes é essencial para aproximar CT\&I.

Como proposta, o Plano de Estado 2018-2030 (CNA e Conselho do Agro, 2018, p. 94) apresenta diretrizes que auxiliam o embasamento dessa discussão:

- aperfeiçoar as ferramentas de gestão de órgãos fundamentais para a inovação tecnológica;

- fortalecer as relações com o setor produtivo, com o objetivo de estabelecer as prioridades de pesquisas que possam ser definidas em conjunto;

- promover as gestóes administrativas necessárias, que permitam interaçáo direta e dinâmica entre a iniciativa privada e os órgãos públicos; e

- desenvolver pesquisa agropecuária focada na geração de conhecimentos e tecnologias de impacto, diminuindo-se a burocracia e as atividades-meio, bem como resgatando a autonomia e a flexibilização das operaçóes de CT\&I.

No âmbito da governança pública, segundo a OCDE (OECD, 2015), a estrutura tradicional e os métodos do Estado não são mais suficientes para resolver os problemas complicados que atravessam fronteiras setoriais e nacionais. Para a entidade, o setor público precisa tornar-se mais estratégico e ágil, com o objetivo de identificar os desafios iminentes e ajustar-se rapidamente. Corroborando com essa visão, Vieira Filho, Gasques e Ronsom (2020) afirmaram que os desafios poderão ser alcançados com contínuos investimentos na construção de um ambiente capaz de responder mais rápido aos problemas contemporâneos - dado que os agentes necessitam de maior capacidade de absorção, tanto no processo de geração de novos conhecimentos e tecnologias, quanto em suas aplicaçóes em campo.

Dado o exposto, considera-se o desempenho da tecnologia e da inovação como um motor de desenvolvimento econômico e social. Propóe-se uma discussão sobre a preparação institucional e técnica para o futuro da inovação agropecuária no Brasil, por meio da observação do contexto dos ecossistemas de inovação. Esses ecossistemas desempenham um papel crucial para impulsionar o desenvolvimento econômico dos países. De acordo com Reeves et al. (2020), por meio de colaboração e orquestração de seus agentes, é possível moldar o ambiente para criar benefícios mútuos e permanecer conectado às oportunidades emergentes. 


\subsection{Ecossistemas de inovação como base para mudança institucional e técnica}

O setor público busca aperfeiçoar o Sistema Nacional de Inovação (SNI). O desempenho do SNI foi objeto de diversos estudos na área da economia da inovação. ${ }^{3}$ Nelson (2006) discutiu a necessidade de mecanismos de coordenação, com o objetivo de assegurar o trabalho das atividades econômicas que envolvem múltiplos atores nesses ambientes. Lundvall et al. (2002) observaram o foco da teoria na ampliação conceitual e a necessidade de aprofundar o entendimento da dinâmica sobre como estabelecer açóes práticas para seu desenvolvimento.

Os ecossistemas de inovação têm sido discutidos com o objetivo de complementar a teoria de SNI, por meio de uma perspectiva aplicada. Gomes et al. (2018) buscaram elucidar os termos, afirmando que a concepção de ecossistemas não deve ser confundida com o conceito de SNI, que seria mais voltado para discussão de políticas públicas. As diferenças, no entanto, ainda não estáo consolidadas na literatura. Os ecossistemas de inovação são estudados nas economias industrializadas por mais de quarenta anos, mas estáo apenas começando a ser apreciados no contexto de economias emergentes (Hoffecker, 2019). Esclarecimentos conceituais podem auxiliar o entendimento da abordagem.

Granstrand e Holgersson (2020) definem um ecossistema de inovação como sendo um conjunto de atores em evolução, atividades e artefatos, bem como instituiçóes e relaçóes, que sáo importantes para o desempenho inovador de um ator ou de uma população de atores. Adner (2006, p. 2, tradução nossa) descreve ecossistema de inovação como "os arranjos colaborativos por meio dos quais as empresas combinam suas ofertas individuais em uma solução coerente, voltada para o cliente". Zahra e Nambisan (2012, p. 225, tradução nossa) consideram o ecossistema de inovação como "um grupo de empresas - e outras entidades, incluindo-se indivíduos - que interagem e compartilham um conjunto de dependências à medida que produzem os bens, as tecnologias $\mathrm{e}$ os serviços que os clientes precisam”.

Jing e Xiong-Jian (2011) resumem características comuns dos ecossistemas de inovação, tais como: um grande grupo de organizaçóes; interconectividade e interdependência; e coevolução. Para Carayannis e Campbell (2009), pessoas, cultura e tecnologia

3. Ver, por exemplo, Freeman (1995), Edquist e Johnson (1997), Lundvall et al. (2002), Lundvall (2007), Groenewegen e Steen (2006) e Fagerberg, Lundvall e Srholec (2018). Para variações acerca do entendimento de SNI, ver: sistemas tecnológicos (Carlsson e Jacobsson, 1997); sistemas setoriais de inovação (Breschi e Malerba, 1997); e sistemas regionais de inovação (Cooke, 1996; Maskell e Malmberg, 1999). 
interagem para catalisar a criatividade, desencadear invenções e acelerar a inovação por intermédio das disciplinas científicas e tecnológicas, dos setores público e privado, tanto em estratégias top-down, orientadas por políticas, quanto por intervençôes bottom-up, baseadas em empreendedorismo. Essas definiçôes demonstram a complexidade de atores que interagem em diferentes níveis do processo de inovação.

Uma característica de ecossistema de inovação que chama atenção está relacionada à liderança. Essa complexa rede de agentes pode ser liderada por um ator fundamental (Iansiti e Levien, 2004) ou por um líder de plataforma (Gawer e Cusumano, 2008). De acordo com Moore (1993), embora o ponto central possa mudar com o tempo, o papel do líder é valorizado pelo resto da comunidade. Essa liderança permite que todos os membros do ecossistema invistam em um futuro compartilhado, no qual esperam lucrar juntos. Tais ideias estáo alinhadas ao conceito de orquestrador de redes de inovação, discutido por Dhanaraj e Parkhe (2006). Ao líder, seria responsável a preservação, a exploração e o gerenciamento do grupo. Esses aspectos devem ser observados em relaçáo ao papel de um orquestrador, tanto no desenvolvimento quanto na renovação institucional coletiva.

Existiriam diferentes tipos de ecossistemas de inovação. As atividades de pesquisa e desenvolvimento (P\&D), conforme sugeridos por Nambisan e Baron (2013), são estudadas no conjunto de entidades, como centros de pesquisa ou até mesmo departamentos de P\&D das firmas, que desenvolvem inovaçóes, como apontado por Zahra e Nambisan (2012). Pode-se considerar que esses tipos de ecossistemas incluem em sua formação, entre outros exemplos, fornecedores, entidades reguladoras, órgãos de definição de padrôes, instituiçóes de pesquisa, provedores de tecnologia, universidades, empresas e outras organizaçôes complementares (Teece, 2007; Iansiti e Levien, 2004; Carayannis e Campbell, 2009). Essa discussão será focada na perspectiva de grupos de instituiçôes de pesquisa.

Termos distintos como ecossistemas de negócio e ecossistemas de inovação podem ser encontrados na literatura. Para Moore (1993), todo ecossistema de negócio ${ }^{4}$ se desenvolve em quatro estágios distintos: nascimento, expansáo, liderança/comando e autorrenovaçáo - ou, ao contrário, morte. Nambisan e Baron (2013) sugeriram que o desempenho e a sobrevivência dos membros estáo intimamente ligados às do ecossistema. Rubens et al. (2011) utilizam o termo ecossistemas de inovação, referindo-se a um aspecto vital caracterizado por um realinhamento contínuo de relaçóes sinérgicas que promovem o

4. As primeiras definições do conceito de ecossistema de inovação, de acordo com uma revisão de Gomes et al. (2018), partiram do conceito de ecossistema de negócios. 
crescimento harmonioso do sistema em resposta ágil às mudanças internas e às forças externas. Iansiti e Euchner (2018) afirmam que alguns organismos precisariam de agilidade para sobreviver em um ecossistema de inovação.

Considerando-se o exposto, volta-se à necessidade de melhor compreensão da autorrenovação de ecossistemas e da ideia de agilidade. O primeiro aspecto será abordado na subseção 3.2.1, levando-se em conta a perspectiva de inovação em gestão. De forma complementar, não se pode deixar de tratar das mudanças de paradigma que têm ocorrido na pesquisa agrícola. Uma vez entendido os novos moldes em que a pesquisa agrícola tem buscado se estruturar, na subseção 3.2.2 apresenta-se a abordagem ágil, que tem sido empregada por organizaçóes que buscam sobrevivência, como inovação em gestão voltada para melhoria de desempenho em ambientes complexos.

\subsubsection{Autorrenovação de ecossistemas e mudanças de paradigma na pesquisa agrícola}

A autorrenovação dos ecossistemas é vista pela ótica da inovação na sua gestão, como meio de trazer benefícios para o desempenho do trabalho e a sociedade. Esse poderia ser um dos meios para endereçar o trabalho institucional criativo na expansão da agricultura, incentivado por Crestana, Contini e Rodrigues (2018) e apresentado anteriormente.

O que seria, entấo, inovação em gestão? Como é possível distingui-la de outros processos da organização? Quais são os processos pelos quais esta ocorre?

Para Birkinshaw, Hamel e Mol (2008), pode ser definida como uma mudança inédita na forma, na qualidade ou no estado ao longo do tempo das atividades de gerenciamento em uma organizaçáo. Ao questionar-se sobre o que exatamente seria inovado, surgem dois níveis de análise. No nível mais abstrato, estão os "corpos razoavelmente estáveis de conhecimento, um sistema de suposições, princípios aceitos e regras de procedimento" (Kramer, 1975, p. 47, tradução nossa). No nível mais operacional, estáo as práticas, os processos e as técnicas de gestão (Alange, Jacobsson e Jarnehammar, 1998; Guillén, 1994) como diferentes facetas, regras e rotinas pelas quais o trabalho é realizado diariamente nas organizaçóes. Nesses termos, a perspectiva operacional é o nível no qual as mudanças observáveis ocorrem e o processo de inovação em gestão pode ser testemunhado.

De acordo com Birkinshaw, Hamel e Mol (2008), por um lado, os papéis dos agentes internos e externos ganham elevada importância na transformação organizacional, e, por isso, é importante examinar até que ponto são capazes de assumir papéis de agentes de mudança e o lócus da inovação gerencial para a organizaçáo que desejar se transformar. 
Por outro lado, Schaffer (2017) chama atenção que todo gerenciamento se trata de mudanças, e os líderes devem ver a mudança não como um disruptor ocasional, mas como a própria essência do trabalho de gestão. A organização deve, assim, passar de meses gastos em criar um plano abrangente, para tornar-se mais orientada para a mudança e concentrar-se em questóes que não estão sendo cumpridas, com metas de curto prazo e testes rápidos de adaptação focados em resultados, buscando incorporar novas formas de trabalhar. Na agricultura, aspectos similares são abordados por Klerkx, Mierlo e Leeuwis (2012), que discutem a necessidade de refletir sobre os processos de monitoramento da inovação e a necessidade de repensar os ciclos produtivos de aprendizagem para a recombinação criativa de conhecimento e recursos nas organizaçóes, em prol de melhor desempenho.

Considerando-se tais aspectos, para a realidade da pesquisa agrícola, quais seriam as abordagens de inovação em gestão mais adequadas diante dos desafios contemporâneos?

Ao longo dos anos, os sistemas de inovação na agricultura têm sido cada vez mais reconhecidos como sistemas adaptativos complexos, e sua evolução indica mudanças no paradigma para pesquisa agrícola, que podem influenciar essa discussão. Tais mudanças podem ser apreciadas, por exemplo, em Douthwaite e Hoffecker (2017), que comparam a abordagem de pesquisa praticada até a década de 1990 com uma abordagem que vem se destacando desde os anos 2000 e propóe-se a ser ciente ou sensível à complexidade contemporânea, conforme detalhes apresentados no quadro 1 .

QUADRO 1

Comparação entre abordagem linear da pesquisa agrícola e a abordagem sensível à complexidade

\begin{tabular}{|c|c|c|}
\hline Características & Abordagem linear & Abordagem sensível à complexidade \\
\hline Nome & Transferência de tecnologia ou pipeline & Sistema de inovação agrícola \\
\hline Era & Dos anos 1960 aos anos 1990 & Desde os anos 2000 a atualidade \\
\hline $\begin{array}{l}\text { Modelo mental e } \\
\text { atividades }\end{array}$ & Fornece tecnologia para o próximo usuário & $\begin{array}{l}\text { Codesenvolve inovação envolvendo processos e parcerias com } \\
\text { vários atores }\end{array}$ \\
\hline $\begin{array}{l}\text { Conhecimento e } \\
\text { disciplinas }\end{array}$ & $\begin{array}{l}\text { Orientado por disciplina única - por exemplo, melhoramento } \\
\text { de plantas }\end{array}$ & Perspectiva transdisciplinar e holística \\
\hline Direcionadores & Impulsionado pela pesquisa & $\begin{array}{l}\text { Capacidade de resposta a contextos em mudança, padrões de } \\
\text { interação }\end{array}$ \\
\hline Fonte de inovação & Cientistas & Vários atores, plataformas de inovação \\
\hline $\begin{array}{l}\text { Papel dos } \\
\text { agricultores }\end{array}$ & Adotantes ou retardatários & $\begin{array}{l}\text { Parceiros, empreendedores e inovadores apresentando } \\
\text { demandas }\end{array}$ \\
\hline Papel dos cientistas & Inovadores & Parceiros, um entre muitos que respondem às demandas \\
\hline $\begin{array}{l}\text { Principais mudanças } \\
\text { buscadas }\end{array}$ & Benefícios resultantes da adoção da tecnologia & $\begin{array}{l}\text { Mudança institucional, aumento da capacidade do sistema } \\
\text { para inovar }\end{array}$ \\
\hline Dinâmica & A pesquisa é iniciada de acordo com uma agenda predefinida & $\begin{array}{l}\text { A intervenção começa construindo relacionamentos e } \\
\text { confiança por meio de uma agenda de pesquisa aberta }\end{array}$ \\
\hline
\end{tabular}

Fontes: Douthwaite e Hoffecker (2017), adaptado de Klerkx et al. (2012) e Douthwaite (2016). 
Douthwaite e Hoffecker (2017) afirmam que, sem considerar as características apresentadas no quadro 1, as agências de pesquisa perdem importantes caminhos alternativos, por meio dos quais podem melhorar o desempenho do sistema agrícola e gerar impacto no desenvolvimento sustentável. Os autores salientam que existem poucos exemplos concretos que consideram essas características. Propostas sáo discutidas, sem olhar pela perspectiva operacional, da inovação gerencial abordada no início desta subseção e sem mencionar o conceito de agilidade.

Conforme Vieira Filho, Gasques e Ronsom (2020), aponta-se a agilidade como potencial caminho para mudanças institucionais no agronegócio, mas não se discutem os meios de desenvolvimento. A subseção a seguir busca contribuir para a discussão, apresentando como a abordagem de gestáo ágil poderia ajudar as organizaçóes dos ecossistemas de inovação agrícola a enfrentar seus desafios.

\subsubsection{Agilidade como estratégia para vencer os desafios da inovação agrícola}

O comportamento de um sistema de inovação agrícola deve ser estudado em uma estrutura dinâmica que permita análise da interação multidirecional entre os atores (Esposti, 2002). Quando tais atores são capazes de responder rapidamente, tem-se um diferencial competitivo (Cohen e Levinthal, 1990; Rosenberg, 1990).

O termo "agilidade" tem sido discutido em todo o mundo, como uma maneira de ganhar competitividade e melhorar as capacidades de inovaçáo dos ambientes a que se destinam (Sull, 2009). Conforto (2013) listou três principais razóes para se adotar métodos ágeis em busca de agilidade: reduzir o time-to-market; melhorar a gestão de mudanças e prioridades nos projetos; e aumentar a produtividade. Na esfera do setor público (OECD, 2015), aborda-se a agilidade estratégica como fator de adaptação diante de desafios e oportunidades do cenário socioeconômico.

A gestão ágil foi pensada inicialmente para proporcionar uma gestão mais leve e dinâmica de projetos, por meio de um conjunto de princípios como flexibilidade, simplicidade e iteração (Beck et al., 2001; Amaral et al., 2011). Há, porém, uma tendência de adoção das metodologias ágeis em grande escala (Paasivaara et al., 2013; Dingsøyr e Moe, 2014).

Corroboram com essa visão Rigby, Sutherland e Takeuchi (2016), que afirmaram que os métodos ágeis estariam em expansão e maduros para serem utilizados em grande escala em empresas de diversas áreas. Ao comentar casos de aplicação na John Deere e General Eletric, os autores reiteram que, além de reduzir o risco, tais métodos possibilitam 
que produtos e soluções tecnológicas sejam disponibilizados para o mercado de maneira mais rápida e previsível.

Os ambientes apropriados para abordagens ágeis, para Rigby, Sutherland e Takeuchi (2016), seriam ambientes de inovação que têm como característica, entre outras, a existência de problemas complexos, para os quais as soluçóes muitas vezes são desconhecidas, as especificações de produtos e serviços sofrem mudanças, os avanços criativos para o mercado são importantes e a colaboração interfuncional é vital.

A agilidade é um conceito dinâmico, segundo Floricel e Piperca (2018), voltado para ambientes com características de volatilidade, incertezas, complexidades e ambiguidade. Tais ambientes, de acordo com San Cristóbal et al. (2019), são sujeitos às mudanças tecnológicas, bem como à diversidade de atores emodelos de negócios. Essas características seriam encontradas em organizaçôes e ecossistemas de inovação. Tais estudos não discutem como desenvolver ou avaliar a agilidade nesses ambientes.

A falta de estudos que orientem o desenvolvimento da agilidade em ambientes como ecossistemas gera preocupaçóes. Teece, Peteraf e Leih (2016), por exemplo, discutiram que era preciso saber quando - e quanta - agilidade é necessária para obtenção de um trade-off entre aspectos econômicos e gerenciais. Além disso, haveria limitações quanto ao gerenciamento de tensóes relacionadas a objetivos conflitantes entre as necessidades do cliente versus estratégia da organização (Lewis, 2000, Sweetman e Conboy, 2013) e o equilíbrio entre agilidade e disciplina (Boehm e Turner, 2004).

As referências primárias desta pesquisa ${ }^{5}$ focam em áreas de conhecimento específicas - por exemplo: agilidade em organizações de manufatur; agilidade no processo de desenvolvimento de produto; e agilidade no gerenciamento de projetos. Há indícios, portanto, de que esclarecimentos e desenvolvimento de pesquisas que tratam dos desafios técnico-científicos são necessários. No âmbito dos ecossistemas de inovação, reúnem-se as principais definiçóes e características de agilidade para atores de ecossistemas de inovação, como o objetivo de entender como o conceito está sendo compreendido e utilizado em tais ambientes.

5. Confira Goldman, Nagel e Preiss (1995); Gunasekaran (1999); Nagel e Dove (1991); Sharifi e Zhang (2001); Schwaber (2004); e Cooper e Edgett (2009). 
$\mathrm{Na}$ revisão da literatura, identificou-se que a agilidade poderia ser desenvolvida em diferentes níveis em um ecossistema, como mostra a figura 1. Para o primeiro nível do ecossistema, chama-se atenção, por exemplo, para o uso da abordagem de gestão ágil, com o objetivo de alinhar uma visão geral de atuação em setores industriais (Vidmar, 2019; Kuivalainen, Kunttu e Kohtamaki, 2020), com apoio de brokers ou agentes de inovação no setor agropecuário (Klerkx, Arts e Leeuwis, 2010); gerenciar políticas e estratégias setoriais (Argyropoulou, Soderquist e Loannou, 2019; Kuivalainen, Kunttu e Kohtamaki, 2020); estabelecer interaçóes entre indivíduos (Vidmar, 2019); promover o comportamento empreendedor (Katzy e Crowston, 2008); e melhorar o desempenho (Argyropoulou, Soderquist e Ioannou, 2019).

Para o nível das organizaçóes, encontra-se o conceito empregado para melhoria de maturidade e meio de resposta para mudanças (Weiblen e Chesbrough, 2015; Battistella et al., 2017); desenvolvimento de uma cultura de inovação (Pérez-Bustamante, 1999); aprimoramento de desempenho (Cooper, 2016; Paasivaara et al., 2018); entre outros exemplos. O potencial do conceito de agilidade é avaliado em Ronsom e Amaral (2019) para um caso de organizaçôes de C\&T da Empresa Brasileira de Pesquisa e Inovação Industrial (Embrapii), chamando atenção quanto à gestão de recursos financeiros.

Para os níveis de programas, portfólios e projetos, especificamente em ambiente com características de ecossistemas, a agilidade tem sido utilizada para facilitar a implementação de projetos de inovação (Dupont, 2019; Conforto e Amaral, 2016; Sweetman e Conboy, 2018), pela aplicação de métodos e técnicas ou modelos amplos de gestão ágil (Sweetman e Conboy 2018; Cooper, 2014; 2016). Desse modo, objetiva-se a liderança e o desenvolvimento de equipes (Wilson e Doz, 2011; Rigby, Sutherland e Takeuchi, 2016; Krstic, Skorup e Lapcevic et al., 2018).

Esta pesquisa possibilitou constatar que, do ponto de vista conceitual, a agilidade encontra-se em estágio inicial de maturidade para o domínio de ecossistemas de inovação. Não há uma linguagem padronizada e reconhecida para esse domínio de aplicaçâo. 
FIGURA 1

Níveis de desenvolvimento da agilidade em ecossistemas de inovação

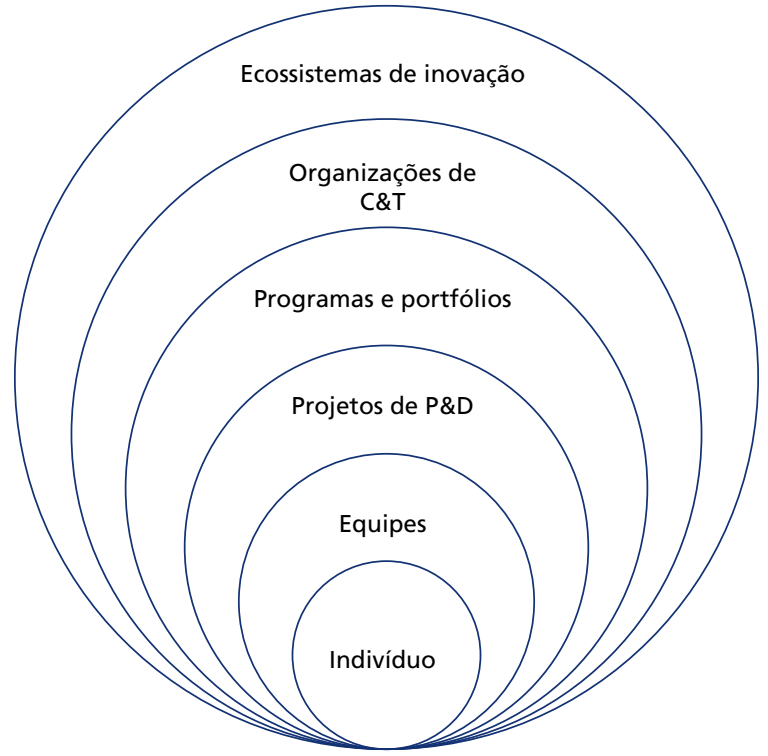

Elaboração dos autores.

Conforto et al. (2016) apresentam uma definição do termo de agilidade como sendo uma habilidade da equipe de projeto de mudar rapidamente os planos de projetos como resposta às necessidades das partes interessadas, demandas de mercado ou tecnologia, com o propósito de atingir melhor desempenho do projeto ou produto em um ambiente inovador e dinâmico (Conforto et al., 2016, p. 8).

A OCDE (OECD, 2015) considera a ideia de agilidade estratégica para o setor público, como possibilidade de uma visão mais ampla do conceito, que seria desenvolvido por meio de três dimensões, descritas a seguir.

1) Sensibilidade da estratégia: capacidade de previsão, bem como antecipação de tendências de mercado, socioeconômicas e ambientais, alinhadas ao gerenciamento de riscos e ao pronto ajuste de estratégias.

2) Fluidez de recursos: capacidade de movimentar recursos (pessoal e financeiro) em resposta às mudanças de prioridades, aumentando-se a eficiência e a produtividade e fornecendo serviços públicos mais eficazes.

3) Compromisso coletivo: a adesão a uma visão comum e ao conjunto de objetivos gerais, com o objetivo de orientar o trabalho individual e coordenado entre os atores públicos. A questão da gestão de recursos financeiros não é comumente encontrada em outras definições de agilidade. 
Klerkx, Arts e Leeuwis (2010) discutem sistemas adaptáveis, considerando a avaliação contínua dos sistemas de inovação agrícola para realizar seus objetivos de inovação, no ambiente institucional em constante mudança, na procura de janelas de oportunidade para reagir constantemente e, por sua vez, modificar ativamente em seu favor.

Conforme exposto, náo há entendimento padronizado sobre o conceito para $\mathrm{o}$ domínio estudado. Essa seria uma lacuna que iria requerer maiores esforços de pesquisa para esclarecimento. Embora uma melhor definição de agilidade voltada para ecossistemas de inovação possa ser buscada em termos conceituais, o que se tem disponível é que, em termos práticos, a agilidade é desenvolvida por meio da abordagem de gestáo ágil.

No âmbito de gestão de projetos, foi estabelecido um conjunto de características voltado para ajudar na compreensão das diferenças da gestão ágil em relaçáo a uma gestão tradicional. Os diferenciais, conforme sintetizado por Amaral et al. (2011), seriam: autogestão das equipes; planejamento iterativo; envolvimento do cliente e simplicidade; e utilização de visão ${ }^{6}$ no lugar de escopo.

Em síntese, de acordo com Amaral et al. (op. cit.), a abordagem ágil prima por princípios como: flexibilidade do processo para absorver mudanças; iteraçôes e entregas parciais - para otimizar o processo de validação; interação e comunicação entre os membros de equipes e principais interessados; simplicidade pelo emprego de técnicas visuais de gestão; tomada de decisão participativa; autogestão e auto-organização; busca de excelência técnica; e agregar valor para o cliente e a equipe do projeto.

Uma série de métodos e técnicas de gerenciamento é aplicada para desenvolvimento da agilidade. Entre as ferramentas mais comuns para seu desenvolvimento, estão modelos de referência, modelos de avaliação, painéis visuais, indicadores, sistemática de reuniôes e sistema de informação (Amaral et al., 2011; Highsmith, 2004; Schwaber, 2004; Cohn, 2005). Tais métodos e técnicas, muitas vezes, precisam ser adaptados para serem incorporados nos processos existentes das organizaçôes (Rohunen, Rodriguez e Kuvaja, 2010; Campanelli e Parreiras, 2015; Dyba e Dingsoyr, 2009).

6. De acordo com Benassi, Amaral e Ferreira (2016, p. 14, tradução nossa), "a visão (de um produto) é definida como: um conjunto de artefatos que descrevem o resultado (...) por intermédio de elementos visuais e textuais, que devem ser elaborados de forma concisa e coletiva - por membros da equipe do projeto e do cliente -, em alinhamento com a estratégia apoiada pelo projeto, e ser capazes de desafiar a equipe em busca de soluções inovadoras". 
No âmbito dos ecossistemas de inovação, observa-se a necessidade de pensar nas características para o desenvolvimento da agilidade e nas formas de medi-la.

Em termos de medição de agilidade, Conforto et al. (2016) relacionam dois fatores: i) a flexibilidade das partes para mudar os planos de projetos; e ii) o envolvimento ativo do cliente - ou seja, a participação desses entes na solução tecnológica objeto de desenvolvimento do projeto. No caso dos ecossistemas, quais instrumentos, planos e estratégias precisam ser flexíveis? E sobre o envolvimento de partes interessadas, quais atores podem ter sinergias e influenciar os resultados de estratégias e planos?

Em síntese, a revisão da literatura tem gerado um conjunto de características principais para análise e desenvolvimento de agilidade em ecossistemas de inovação: propósitos de utilização; fatores operacionais; níveis de desenvolvimento; fatores ambientais; fatores de desempenho; fatores da liderança; e desafios e limitaçóes. O quadro 2 apresenta exemplos de características de agilidade em ambientes de ecossistemas de inovação.

QUADRO 2

Características de agilidade em ambientes de ecossistemas de Inovação

\begin{tabular}{|c|c|c|}
\hline Dimensão & Exemplos de características & Referências \\
\hline $\begin{array}{l}\text { Propósitos da } \\
\text { abordagem ágil em } \\
\text { ecossistemas }\end{array}$ & $\begin{array}{l}\text { - desenvolvimento da agilidade estratégica (sensibilidade da } \\
\text { estratégia, fluidez de recursos e compromisso coletivo) } \\
\text { - gerenciamento de políticas e estratégias de setores ou redes } \\
\text { de inovação; } \\
\text { - melhoria de desempenho; } \\
\text { - maturidade para inovar; } \\
\text { - facilitação de implementação de projetos de inovação; e } \\
\text { - criação de valor. }\end{array}$ & $\begin{array}{l}\text { Katzy e Crowston (2008); OECD (2015); } \\
\text { Weiblen e Chesbrough (2015); Krstic, } \\
\text { Skorup e Lapcevic (2018); Argyropoulou, } \\
\text { Soderquist e loannou (2019); Vidmar (2019); } \\
\text { Kuivalainen, Kunttu e Kohtamaki,. (2020) }\end{array}$ \\
\hline $\begin{array}{l}\text { Fatores operacionais } \\
\text { sobre como } \\
\text { desenvolver } \\
\text { agilidade }\end{array}$ & $\begin{array}{l}\text { - adaptação de estruturas gerenciais } \\
\text { - alinhamento de uma visão/ mensagem fundamental de } \\
\text { agilidade; } \\
\text { - aplicação de métodos e técnicas; } \\
\text { - implementação gradual/em estágios (testes-piloto); e } \\
\text { - aprendizado contínuo. }\end{array}$ & $\begin{array}{l}\text { Vidmar (2019); } \\
\text { Cooper (2014; 2016); Rigby, Sutherland e } \\
\text { Takeuchi (2016); Krstic, Skorup e Lapcevic } \\
\text { (2018); Sweetman e Conboy (2018) }\end{array}$ \\
\hline $\begin{array}{l}\text { Nível de } \\
\text { desenvolvimento }\end{array}$ & $\begin{array}{l}\text { - ecossistema; } \\
\text { - organizações do ecossistema (orquestradores e demais); } \\
\text { - programas e portfólios; } \\
\text { - projetos; } \\
\text { - times (times de projetos e agentes de inovação); e } \\
\text { - indivíduos. }\end{array}$ & $\begin{array}{l}\text { Klerkx, Arts e Leeuwis (2010); Conforto e } \\
\text { Amaral (2016); Battistella et al. (2017); } \\
\text { Sweetman e Conboy (2018); Vidmar (2019) }\end{array}$ \\
\hline Fatores ambientais & $\begin{array}{l}\text { - competitividade; } \\
\text { - constantes mudanças (paradigma da pesquisa agrícola); } \\
\text { - influência do setor público/privado; e } \\
\text { - mundo Vuca (volatility, uncertainty, complexity, ambiguity). }\end{array}$ & $\begin{array}{l}\text { Sull (2009); OECD (2015); Douthwaite e } \\
\text { Hoffecker (2017); } \\
\text { Floricel e Piperca (2018); San Cristóbal et } \\
\text { al. (2019) }\end{array}$ \\
\hline
\end{tabular}




\begin{tabular}{|c|c|c|}
\hline Dimensão & Exemplos de características & Referências \\
\hline $\begin{array}{l}\text { Fatores de } \\
\text { desempenho }\end{array}$ & $\begin{array}{l}\text { - flexibilidade/frequência de mudança de estratégias e planos; } \\
\text { - envolvimento de partes interessadas; e } \\
\text { - liderança. }\end{array}$ & $\begin{array}{l}\text { Conforto et al. (2016); } \\
\text { Backlander (2019); } \\
\text { Vidmar (2019); Kuivalainen, Kunttu e } \\
\text { Kohtamaki (2020) }\end{array}$ \\
\hline Fatores de liderança & $\begin{array}{l}\text { - funções e estilos dos líderes; } \\
\text { - autonomia de equipes; } \\
\text { - promoção da autogestão; e } \\
\text { - comportamento empreendedor. }\end{array}$ & $\begin{array}{l}\text { Pérez-Bustamante (1999); } \\
\text { Battistella et al. (2017); } \\
\text { Backlander (2019) }\end{array}$ \\
\hline $\begin{array}{l}\text { Desafios e } \\
\text { limitações }\end{array}$ & $\begin{array}{l}\text { - gerenciamento de tensões relacionadas a objetivos } \\
\text { conflitantes e necessidades do cliente versus estratégia da } \\
\text { organização equilíbrio entre controle e liberdade; e } \\
\text { - cooperação e coordenação em equipes de especialistas com } \\
\text { diferentes formações. }\end{array}$ & $\begin{array}{l}\text { Lewis (2000); } \\
\text { Amaral et al. (2011); } \\
\text { Sweetman e Conboy (2018). }\end{array}$ \\
\hline
\end{tabular}

Elaboração dos autores.

A partir dessas características encontradas na literatura, buscou-se uma visão pragmática, analisada de acordo com a realidade do ecossistema de inovação agrícola brasileiro. A Embrapa, como organização de pesquisa agrícola de grande importância no cenário nacional, tem estado aberta para tal discussão. As subseçôes a seguir abordam a evolução na gestão da empresa e fazem uma análise preliminar sobre as possíveis características de agilidade identificadas na instituição.

\subsection{A Embrapa e uma trajetória de evolução gerencial}

As organizaçóes de pesquisa que compóem o ecossistema de inovação na agricultura têm papel fundamental na transformação de conhecimento para novas aplicaçóes para o mercado e o campo.

De acordo com Vieira Filho e Fishlow (2017), o modelo de pesquisa brasileiro tem se desenvolvido desde a década de 1950, entre outros aspectos, pela coordenação de iniciativas com diversas instituiçóes promotoras da inovação no agronegócio (institutos de pesquisa estaduais, agências de extensão rural, universidades e empresas do setor privado). ${ }^{7}$ A partir da criação da Embrapa e dos investimentos em ciências agrárias, segundo os autores, criou-se um aparato institucional para transformar a agricultura brasileira baseada na C\&T e investiu-se neste.

7. Exemplos de universidades: Escola Superior de Agricultura Luiz de Queiroz (Esalq) da USP; Universidade Federal de Viçosa (UFV); e Escola Superior de Agricultura de Lavras (Esal). Exemplos de institutos de pesquisa estaduais: Instituto Agronômico de Campinas (IAC); e Instituto Rio Grandense do Arroz (Irga), conforme Vieira Filho e Fishlow (2017). 
Para Alves (2001), o modelo da Embrapa é adequado para a pesquisa aplicada que precisa focalizar-se em produtos, regióes e temas e procura dar espaços aos estados, à iniciativa particular e a universidades. A instituição é um caso de inovação institucional bem-sucedido; caracteriza-se por escala de operação, descentralização espacial, especialização das unidades de pesquisa, valorização do treinamento e visão de uma agricultura baseada na C\&T (Alves, 2010). De acordo com Iansiti e Levien (2004) e Dhanaraj e Parkhe (2006), pode-se entender que a Embrapa assume o papel de orquestrador de uma rede de instituiçóes de pesquisa.

As organizações de pesquisa, como afirmam Alves e Souza (2007), devem ser capazes de responder prontamente à sociedade, aumentando assim a confiança no sistema como um todo. A Embrapa, no entanto, tem sofrido diante da voraz e crescente burocracia, que tem reduzido progressivamente sua força motriz em comparação a sua atuação mais ágil do passado (Crestana e Magalhães, 2007; Crestana e Figueiredo, 2008; Alves, 2015).

Crestana, Contini e Rodrigues (2018) e Alves e Souza (2007) apontaram a necessidade de se discutir o modelo de pesquisa. Eles observam os desafios para uma perspectiva mais ampla, da rede de inovação e suas organizaçóes, e para processos específicos de pesquisa, conforme exemplos a seguir.

1) Manter financiamento de pesquisa, desenvolvimento e inovação (PD\&I), administrados de maneira compartilhada entre atores públicos e privados. Mecanismos foram citados como os estabelecidos na gestão da Embrapii e na de institutos internacionais, como o Instituto Fraunhofer, na Alemanha.

2) Estimular fomento/incentivo para pesquisas em escalonamento industrial. Não seria uma cultura dos organismos de pesquisa agropecuários, apesar de iniciativas como a Embrapii preverem explicitamente esse tipo de pesquisa.

3) Melhorar significativamente os mecanismos de captação de demanda dos setores produtivos e consumidor e agrícola e urbano, bem como estabelecer claramente açôes concretas com o conjunto de stakeholders de empresas.

4) Descentralizar processos, ao diminuir-se a gigantesca burocracia e resgatar-se a autonomia de unidades descentralizadas da Embrapa na gestão da pesquisa e dos recursos humanos.

5) Enfrentar, com visão e gestão inovadoras, a interação Embrapa-universidade e Embrapa-instituiçóes de fomento à pesquisa.

6) Aperfeiçoar os processos de pesquisa, como o exemplo daqueles de fenotipagem e do algoritmo da empresa KeyGenes. 
Como princípios fundamentais de uma instituição de pesquisa, Alves e Souza (2007) apontaram questôes com a ideia de agilidade:

- o modelo organizacional deve ser flexível e livre de entraves burocráticos, com o objetivo de formular propostas, administrar o orçamento, selecionar prioridades, desenvolver pesquisa, assim como elaborar e executar a política de pessoal;

- é importante minimizar a burocracia para que o pesquisador possa exercer seu papel, aproveitando melhor o tempo investido na pesquisa;

- deve-se estabelecer mecanismos de motivação do pesquisador pelo empreendedorismo;

- é preciso ampliar o pragmatismo da pesquisa, focando-a em problemas de ordem; e

- as unidades de pesquisa precisam ser entendidas pelos pesquisadores e pela sociedade; devem saber evitar a dispersão de esforços e facilitar a interação com os agricultores e o agronegócio.

A seguir, são apresentados exemplos em que a Embrapa já vem buscando melhorias nesse sentido.

Um caso de sucesso é apresentado por Parente et al. (2020), sobre a evolução do setor de sementes de soja no Brasil ao longo de quatro décadas (1973-2015). Os autores discutem o desenvolvimento da capacidade de absorção e o alinhamento entre diversas organizaçóes para o desenvolvimento de conhecimento tácito crítico e ativos complementares. A geraçáo e a disseminaçáo de resultados para os agricultores e outros usuários finais, entre outros fatores, ajudaram a manter a proeminência do setor. O estudo aponta melhoramentos nas habilidades gerenciais da Embrapa, mas não detalha os aspectos de governança, pela perspectiva operacional e pelo conceito de agilidade. Observa-se que o caso pode ter sido apoiado pelo envolvimento de empresas de grande porte do setor.

Silva et al. (2019) apresentam um estudo de caso que indica que a área de TT da unidade da Embrapa Agrobiologia no Rio de Janeiro passou por uma reestruturaçáo recente, que incluiu o intercâmbio e a construçáo coletiva do conhecimento, em seu processo para transformar o empreendedorismo em realidade. Por meio de um modelo participativo, foram envolvidos agentes multiplicadores desde a fase de pesquisa até a fase de transferência da tecnologia. Houve preocupações sobre a construção de diálogo com o público-alvo e a sociedade em geral, tratadas por meio de estudos prospectivos ou implementação de tecnologia, o conhecimento das demandas da sociedade, bem como o estudo de cenários e a priorização de quais necessidades seriam traduzidas em pesquisas.

Além dos exemplos pontuais apresentados, o trabalho de Nascimento (2016) disserta sobre a evolução da dinâmica dos macroprogramas e portfólios da Embrapa. 
Vieira et al. (2020) citam que a Embrapa Agroenergia tem implementado iniciativas na melhoria de sua gestão, inspiradas nas regras do modelo Embrapii. Conforme estudado por Ronsom e Amaral (2019) e Reynolds, Schneider e Zylberberg (2019), apresentam-se características de agilidade em suas organizaçôes de pesquisa.

Observa-se, nas entrevistas realizadas e nos exemplos estudados, que a trajetória de evolução da Embrapa tem sido marcada por uma infraestrutura de inovaçáo mais voltada para a prateleira e a realização de pesquisas por meio de grandes programas. A empresa tem entregado pesquisas ao seu público por meio de TT, em linha com a abordagem discutida por Douthwaite e Hoffecker (2017), com evolução contínua em busca de ajustes na sua atuação. A política de inovação da Embrapa (2018) cita a agilidade como fator de desenvolvimento. Portanto, questiona-se: como pensar em uma Embrapa mais ágil para os próximos anos?

Para um cenário futuro, levantam-se questôes sobre os programas com diretrizes mais rígidas, de longo prazo. Pensando-se em uma gestáo mais dinâmica, perante as mudanças que se tornam cada vez mais constantes, estes seriam adequados para vencer os desafios contemporâneos? Como os portfólios e os projetos poderiam adaptar-se rapidamente às mudanças de ambiente? Quais seriam as estratégias para acompanhamento das partes interessadas e desenvolvimento de uma liderança mais ágil?

Pondera-se que existam iniciativas, como as apresentadas nos casos exemplificados, implementadas por outras unidades da Embrapa e adaptaçôes em curso ainda náo documentadas na literatura e não captadas nas entrevistas, em busca de maior dinamismo para a organização. As entrevistas possibilitaram a identificação de pontos de aprimoramento que sinalizam estratégias e práticas de agilidade. A seguir, são apresentadas tais estratégias e práticas identificadas na empresa.

\section{ESTRATÉGIAS E PRÁTICAS DIRECIONADAS PARA AGILIDADE NA EMBRAPA}

\subsection{Adaptações na estrutura de gestão das unidades da Embrapa}

Em relação a açôes voltadas para adaptação das estruturas organizacionais, foi identificada a estruturação de um núcleo de inovação tecnológica (NIT), como um embrião no que concerne ao determinado na Embrapa central. Tal estrutura teria como critérios e requisitos mínimos o estabelecimento de planos e processos que poderiam ser adaptados 
para a realidade de cada unidade. Isso poderia dar maior flexibilidade para a gestão de recursos em projetos baseados em casos concretos da unidade.

Outra observação foi a menção de grandes oportunidades para o desenvolvimento tecnológico do agronegócio, em função da excepcional diversidade de biomas e do caráter continental do país, parente o mundo. A influência e o impacto da Embrapa podem ser ampliados, caso haja melhoria na capacidade de adaptação da organização quanto a maior exploração de biomas.

Conforme visto, as teorias de agilidade, gerenciamento ágil e modelos adaptativos estão se ampliando, com novos conceitos e ferramentas que buscam expandir essa capacidade. Uma oportunidade para os gestores seria aproveitar-se dessas novas teorias para repensar os mecanismos e as divisóes; enfim, as estruturas gerenciais.

Como exemplo, consideram-se as proposições de novas e dinâmicas estruturas que possam ser ampliadas ou remodeladas de forma mais orgânica, como os laboratórios vivos $^{8}$ da indústria espacial da Escócia (Vidmar, 2019). Outras formas de adaptaçóes de estruturas gerenciais que diminuem barreiras entre setores podem ser encontradas em Bäcklander (2019), no caso do Spotify, no qual são utilizados conceitos de subgrupos por competência (ideia de tribos, pelotóes etc.).

Os exemplos seriam uma alternativa de flexibilização de estruturas de gestão e estão alinhados ao que foi visto na prática de redundância dos NITs, ampliando a capacidade de reação ante as oportunidades de pesquisa. Outras açóes similares poderiam ser consideradas para os núcleos de inovação e as unidades descentralizadas da Embrapa.

\subsection{Adaptações nos instrumentos de gestão das unidades descentralizadas da Embrapa}

Há casos de adaptações em instrumentos do Setor de Prospecçôes e Avaliação de Tecnologia (SPAT) da Embrapa para a realidade da unidade. Assim, considera-se inteligência estratégica para análise de:

- necessidade de novas competências e agentes para atuar na prospecçáo tecnológica, considerando-se releituras de competências dispersas na unidade, com análise de novas oportunidades;

8. Ver, também, Leminen (2015) e Fecher et al. (2020). 
- cenários para orientar carteira de projetos, admitindo-se o uso do technology readiness level (TRL);

- tipos de projetos que podem ser desenvolvidos;

- reconfiguraçóes em processos;

- qualificação de ativos motivados por valoração de mercado; e

- revisão de indicadores, com um novo índice de reputação.

Conforme resultados parciais, foram observadas evidências de adaptações em:

- modelos de avaliação de maturidade em processos de gestão de pesquisa e inovação;

- rearranjos de portfólios de projetos, com o estabelecimento de metas para projetos de inovação em cooperação com o setor privado; e

- antecipação de recursos e autonomia de decisão para tipos específicos de projetos, relativos à inovação.

Como exemplo, ações concernentes a varreduras e prospecção tecnológica, em linha com o termo conhecido na literatura como technology roadmapping (TRM), estariam sendo conduzidas de forma mais dinâmica e com intervalos menores de atualização. A Embrapa pode estar sendo significativamente inovadora nesse sentido, pois o tema começou a ser debatido recentemente e há poucos trabalhos que relacionam os conceitos de TRM e agilidade. Vishnevskiy, Karasev e Meissner (2015) e Carlos, Amaral e Caetano (2018) são raros exemplos. Os primeiros apontaram o problema da falta de roteiros tecnológicos integrados e constantemente atualizados para potencializar estratégias de governo, fabricantes, investidores e redes de inovação. Os segundos desenvolveram um modelo justamente para a atualização contínua de roadmaps, combinando conceitos de agilidade e inteligência competitiva.

Outro exemplo citado anteriormente e que pode auxiliar quanto à adaptação de instrumentos de gestão foi documentado em Reynolds, Schneider e Zylberberg (2019) e Ronsom e Amaral (2019), sobre o caso da Embrapii. Os autores discutiram, entre outros aspectos, a "habilidade de planejar portfólios de projetos e mudar estratégias" e a "habilidade de ajustar estratégias em nível de atuação nacional, com fomento a novos públicos e novas áreas de competência” (Ronsom e Amaral, 2019, p. 8-9) da instituição. No sistema Embrapii, chama atenção a autonomia para as instituições de ciência e tecnologia (ICTs) gerenciarem os recursos dos projetos, apresentado em Reynolds, Schneider e Zylberberg (2019, p. 238). Esse seria um dos poucos casos práticos encontrados na literatura que pode se relacionar à dimensão de flexibilidade de recursos financeiros, apontada no estudo da OCDE (OECD, 2015) para agilidade estratégica. 
Já existe uma unidade da Embrapa que contrata projetos nesse sistema. Esse aprendizado com o sistema Embrapii pode ser internalizado na organizaçáo e recombinado com outras práticas diferenciais da Embrapa. Assim, seria possível atuar para uma futura evolução nos instrumentos de gestão da instituição, de forma a ampliar a agilidade de recursos financeiros e, consequentemente, a agilidade estratégica.

\subsection{Processo iterativo}

Em relação ao processo iterativo para desenvolvimento de adaptaçóes de soluçôes, foram identificadas fraçóes de práticas e métodos da gestão ágil, por meio de:

- revisões periódicas de planos com foco em melhores apostas (priorizações que consideram aspectos financeiros e científicos, bem como seus impactos);

- compartilhamento de "pílulas" semanais com a equipe com as diretrizes do ecossistema da unidade;

- modelo visual leve de planejamento; e

- monitoramento periódico e constante com a equipe por reunióes e webconferences.

Mesmo que tímidas, a existência deste tipo de açôes é um indicativo de busca pela incorporação de práticas ágeis no sistema Embrapa, o que configura um caminho de experimentação e uso de abordagens híbridas de gestão.

Segundo Conforto et al. (2015), os modelos híbridos são a combinaçáo de princípios, práticas, técnicas e ferramentas de diferentes abordagens em um processo sistemático, que visa adequar a gestão ao contexto de negócio e tipo específico de projetos. Esse processo tem como objetivo maximizar o desempenho do projeto e produto, proporcionar um equilíbrio entre previsibilidade e flexibilidade, reduzir os riscos e aumentar a inovação, para entregar melhores resultados de negócio e valor agregado para o cliente.

Um caso real e específico foi relatado por Conforto e Amaral (2016), baseado na abordagem híbrida de gestão (tradicional e ágil). Apresentou-se um modelo de planejamento e monitoramento de projetos, considerando-se um processo iterativo para empresas de base tecnológica. Há, portanto, uma oportunidade para o estudo do hibridismo e seu potencial de aplicaçáo no sistema Embrapa. A contribuição seria baseada em evidências empíricas que apoiam o debate atual sobre os benefícios da combinação de diferentes abordagens de gestão. 
Seja no hibridismo ou na aplicação de métodos ágeis em sua forma original, há grande espaço para pesquisa e aplicação prática de métodos ágeis em uma instituição como a Embrapa, como pode ser observado no exemplo da agenda apresentada por Mergel, Gong e Bertot (2018).

\subsection{Envolvimento de agentes internos e externos}

Em relação ao envolvimento dos membros internos da organização, foi observada uma gestão diretiva alinhada ao compromisso do servidor público, focada em cumprir uma agenda negociável, que considera:

- $\quad$ promover visão de mercado entre indivíduos;

- promover institucionalização de uma nova mentalidade de integração para inovação - não a visão individualizada como era;

- desenvolver perfil analítico e argumentativo - com vistas à mudança de postura;

- capacitar e orientar a equipe para autodesafiar-se; e

- formar agentes de inovação internos, pessoas dedicadas a entender a estrutura da unidade e multiplicá-la.

Quanto ao envolvimento das partes interessadas externas à Embrapa, foi identificada a prática de ranqueamento e alinhamento das iniciativas, que busca sinergias com a estratégia da central e da unidade, para desenhar açóes futuras. Em relação à frequência de interação, foi reconhecida a prática de realização de diálogos constantes sobre políticas do setor - com policy makers - e nichos na rede para construçáo de nova mentalidade. O objetivo seria difundir o papel da organização de ser um catalisador de demandas potenciais em ecossistemas regionais.

A aproximação entre pesquisadores das unidades da Embrapa com os produtores, os atores da área de startups (empreendedores, aceleradoras etc.) e os investidores é um movimento que contribui para a agilidade. A proximidade com o usuário com o desenvolvedor é algo muito valorizado na abordagem de gestáo ágil. Uma organização apenas consegue ser ágil se possui contato com o usuário final, que ajuda a priorizar os esforços em cada projeto. Nos métodos ágeis, existe um papel específico, ${ }^{9}$ representado

9. 0 product owner - ou proprietário do produto - é responsável por maximizar o valor dos produtos resultantes do trabaIho do time de desenvolvimento dos projetos. Para mais detalhes, ver Sutherland e Schwaber $(2017$, p. 6). 
por uma pessoa que conhece ou faz parte do grupo de usuários dos produtos envolvendo a tecnologia. Este busca ajudar a equipe nas decisóes sobre os avanços necessários.

Esse papel e as experiências relatadas poderiam ser observados pela administração da Embrapa e servirem de reflexão para políticas e mudanças estruturais que possam amplificar as práticas ágeis, como fortalecer a voz do cliente e a priorização dos esforços voltados para problemas e dores mais reais. É possível que algumas unidades descentralizadas já operem com visão semelhante - ou seja, já trabalhem com representaçóes fortes de usuários, como foi visto em Parente et al. (2020), mas seria algo a explorar-se de forma mais ampla.

\subsection{Liderança ágil}

No caso da liderança, observa-se o processo de aprimoramento e desenvolvimento das carreiras. Nesse caso, foi possível verificar o discurso alinhado das unidades com aspectos promotores da liderança no contexto dos ambientes ágeis - por exemplo:

- orientações contínuas para desenvolvimento de relacionamentos e foco no propósito (a unidade como provedor de soluçóes e mediador de interesses);

- valorização da trajetória, porém, com foco na unidade como portadora de futuro;

- gerenciamento de alertas, como "se a equipe não entender as adaptaçôes, correrão o risco de fazer trabalhos dispersos"; e

- equipe aprendendo a priorizar ações, considerando a competitividade interna.

No gerenciamento ágil, conforme Backlander (2019), há preocupação quanto ao aspecto de equilibrar a organização formal e informal, com o objetivo de alavancar a dinâmica dos sistemas adaptativos complexos e produzir aprendizagem, criatividade e adaptação nas organizaçóes.

Quanto ao desenvolvimento de lideranças nas unidades entrevistadas, foram identificados os aspectos descritos a seguir.

1) Preocupação com o perfil; por exemplo, o equilíbrio entre experiência e membros jovens com potencial de liderança, capazes de ajudar a construir uma gestáo mais leve.

2) Preocupação com o desenvolvimento de um perfil argumentativo, para que os profissionais sejam capazes de qualificar o retorno da informação e construir novos conhecimentos.

3) Emprego da ideia de autogestão. 
Foi identificado também o uso do conceito de visão para motivação da equipe. A visão é um conjunto de artefatos que objetivam gerar motivação e sensação de desafio para a equipe, por meio de lemas integradores que geram sentimento de comprometimento (Benassi, Amaral e Ferreira, 2016). Na pesquisa, foi citado o uso de um tipo de comunicaçáo com essas características, como meio de manter a orientaçáo constante da unidade sobre o direcionamento em termos de inovação. Em outra ocasião, foram relatadas açôes para a formação de equipes e lideranças segundo esse tipo de orientação.

Esse conjunto de práticas identificadas é um sinal de que as diretrizes para a formação de lideranças que promovam a agilidade, segundo o desenvolvimento e as teorias presentes na área, poderiam servir como um parâmetro para a análise do processo de formação de recursos humanos na empresa. Seguir esse caminho de investigação e experimentação prática pode conduzir à promoção da agilidade na instituiçấo. Compreender melhor os estilos de liderança e como estes podem contribuir para o ambiente da Embrapa seria um esforço válido e interessante para a reflexão do futuro da organizaçáo.

\subsection{Aspectos ambientais}

A governança em ambiente público foi apontada como uma questão a ser melhor desenvolvida. Os entrevistados reconhecem o desafio de ser flexível. Uma cultura forte, amparada em propósitos, é característica típica de organizaçôes ágeis. É possível desenvolver um compromisso coletivo, como forma de integrar comportamentos e ampliar a flexibilidade sem que a instituição perca o controle.

No entanto, observa-se que as áreas da pesquisa nas quais a Embrapa atua envolvem riscos técnicos; por exemplo, químicos e biológicos. São projetos muitas vezes desenvolvidos em áreas com ambientes regulados, cuja experimentação precisa ser equilibrada com a garantia e o controle da qualidade. Devem ser levados em conta, ainda, os princípios da administração pública de legalidade, impessoalidade, moralidade, publicidade e eficiência.

Esses aspectos podem muitas vezes ser divergentes. De um lado, busca-se uma cultura forte para promover uma governança com técnicas mais flexíveis e ágeis. De outro lado, há a necessidade de atender a restriçôes de riscos físicos, segurança alimentar e transparência pública, que, em geral, sobrecarregam os profissionais da organização. Isso poderia ser um problema, mas, no âmbito da pesquisa de ponta em gestão ágil, esse dilema vem sendo tratado e começam a surgir soluçôes, como é o caso dos modelos de gestáo ágil voltados para ambientes regulados. 
Fitzgerald et al. (2013) apresentam discussóes sobre noçóes de conformidade contínua e rastreabilidade ativa. Os autores defendem que as equipes de trabalho deveriam adequar-se para atender ao dinamismo exigido pelas pressóes externas à organização, sem perder o controle; assim, a observação da conformidade ocorreria de forma contínua. Silva (2019) apresentou uma síntese da literatura sobre as práticas utilizadas para adaptaçáo de modelos ágeis voltados para ambientes regulados. E, como citado, Mergel, Gong e Bertot (2018) apresentaram uma agenda de pesquisa sobre a agilidade em organizaçóes governamentais.

Os estudos poderiam contribuir para a discussão sobre redução dos níveis de burocracia e melhoria da governança na Embrapa. Outro aspecto observado no ambiente dessa empresa, que foi estudado, é que os especialistas estáo motivados para promover mudanças na gestão de suas unidades em prol de maior agilidade e flexibilidade. Isso contribui para que uma nova mentalidade seja desenvolvida e disseminada na organização.

\subsection{Desafios e limitações}

Há a confirmação da necessidade de melhorias nos processos de governança da Embrapa. Foi possível demonstrar que parte das respostas dos gestores de unidades para esses problemas está alinhada com tendências e práticas propostas pela teoria de agilidade e gerenciamento ágil.

Vale destacar que o envolvimento de profissionais de diferentes níveis na organização ajuda a capturar os fatores internos e externos sob diferentes perspectivas; porém, isso é sempre um desafio de pesquisa de campo. Dessa forma, o apoio de patrocinadores nas unidades possibilita grande contribuição para a qualidade da proposta. Os gestores consultados disponibilizaram-se como parceiros para dar continuidade ao trabalho em suas unidades, indicando que a administraçáo central tem uma excelente oportunidade para compreender essas experiências e ajudar na disseminação e internalização dessas práticas.

Sugere-se entender o quão a gestão de cada unidade percebe a necessidade de evolução influenciada por fatores internos e externos. Há indícios de que nem todas estariam observando as tendências das agendas globais. Outro aspecto a ser equilibrado no ecossistema seria a visão da organização sobre tecnologias digitais disruptivas avançadas.

O mundo digital traz uma nova forma de competição nos ecossistemas. Isso já é muito evidente em áreas de tecnologias da informação (TIs), e esse movimento pode estar acontecendo com as demais tecnologias voltadas para o agronegócio, especialmente 
nesse contexto da digitalização. Isso significa que não é impossível, dado os mecanismos de desenvolvimentos virtuais, entre outros fatores, que a Embrapa enfrente competição com outras organizações, como redes de pesquisas privadas e startups.

Iansiti e Euchner (2018), que discutem a agilidade como fator fundamental de sobrevivência em ambientes competitivos, analisam as plataformas tecnológicas como ecossistemas de inovação por uma analogia com ambientes biológicos. Nesses ambientes, haveria espécies fundamentais para a evolução natural de um grupo, que atuariam para prover uma estratégia voltada para sua sustentação. A Embrapa pode ser vista com esse papel fundamental para a pesquisa agrícola brasileira, e a sugestão é analisá-la sob o aspecto da agilidade. A incorporação de estratégias e práticas ágeis pode ter um impacto fundamental em todo o ecossistema do agronegócio nacional, mantendo-o competitivo e, mais, fortalecendo e ampliando seu impacto no desenvolvimento do país.

\section{A EMBRAPA COMO ECOSSISTEMA ÁGIL DE INOVAÇÃO}

Segundo as teorias de gestão e os resultados preliminares obtidos, pode-se inferir cenários (uma Embrapa imersa em um forte ecossistema, formado por instituições de pesquisa e diversidade de entidades e associaçóes de agricultores). Tais atores atuariam com uma estratégia de agilidade para ajustamento conjunto das capacidades de inovação e criação de plataformas tecnológicas adaptáveis ao agronegócio.

A Embrapa representaria o papel de líder de tal empreendimento. Estratégias flexíveis e instrumentos de gestão adaptáveis poderiam contribuir para entregar resultados mais rápidos para a sociedade. Conforme o princípio de comprometimento coletivo (OECD, 2015) e a visão institucional de agilidade (Klerkx, Arts e Leeuwis, 2010; Vidmar, 2019), esse possível cenário futuro poderia empreender o desenvolvimento da agilidade como marca fundamental para a trajetória gerencial da instituição, conforme ilustrado na figura 2 . 
FIGURA 2

Trajetória de evolução gerencial da Embrapa e possível cenário futuro

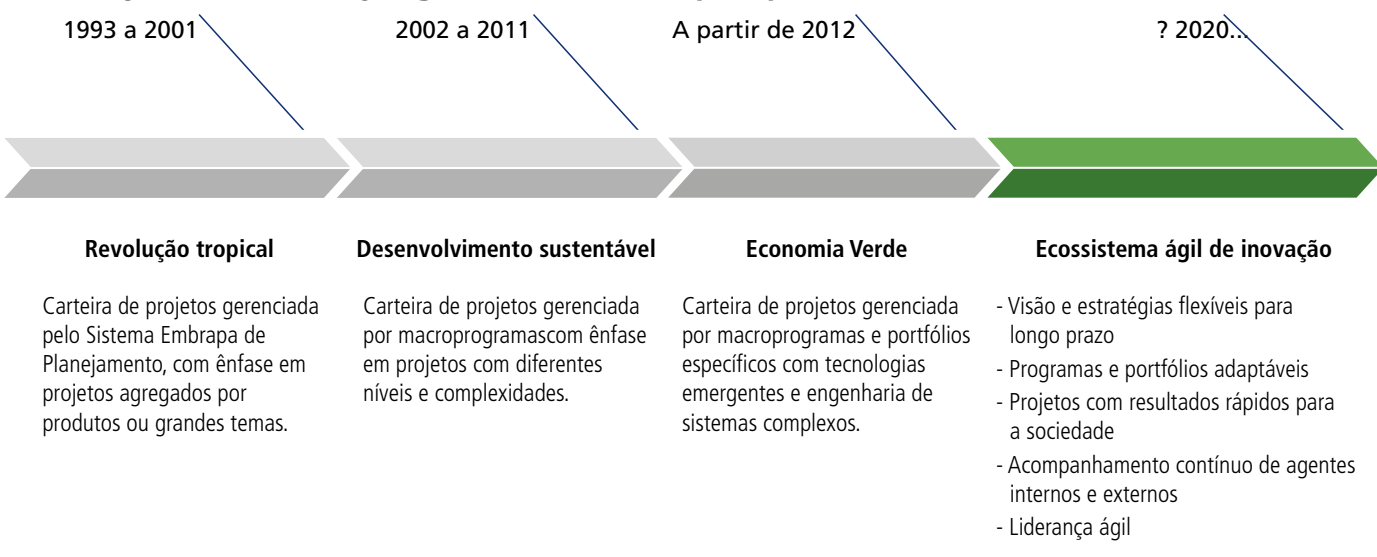

Fonte: Nascimento (2016, p. 60)

Elaboração dos autores.

A figura 2 parte da dinâmica de inovação apresentada em Nascimento (2016, p. 60) e representa a ideia de uma temática de agilidade para uma próxima fase de evolução gerencial da Embrapa. A instituição, como líder de plataforma, daria diretrizes às unidades, observando melhorias em seus níveis de autonomia para adaptaçóes em suas estruturas e seus instrumentos de gestão. Mais ágil, cada unidade fortaleceria seus relacionamentos com organizaçôes públicas e empresariais, bem como com agricultores em seu entorno, atuando para responder às suas necessidades e servindo como exemplo para que eles possam também ampliar essa forma de ação. Um efeito em cadeia como esse pode tornar todo o ecossistema mais responsivo e dinâmico, resultando em maior flexibilidade e capacidade para dar respostas às demandas da sociedade mais rapidamente, em face da complexidade crescente.

O conjunto de estratégias e práticas de agilidade apresentadas deve ser investigado, com apoio da academia, para que seja compreendido em toda a sua extensão e, a partir deste, sejam desenvolvidos testes-piloto, propostas e mecanismos para a disseminação das práticas que foram identificadas como úteis e positivas.

A proposta poderia trazer uma nova forma de pensar o gerenciamento de programas e portfólios da instituição, novas práticas de relacionamento entre unidades, novos serviços para a comunidade e o aprimoramento na visão de longo prazo das unidades. Todos contribuindo para disseminar a concepção de contínua adaptação, unida ao aprendizado de todo um grupo para o fortalecimento do ecossistema de inovação da agricultura brasileira. 


\section{CONSIDERAÇÕES FINAIS}

Este trabalho apresentou uma breve contextualizaçáo do cenário de expansão da agricultura brasileira e indicou os ecossistemas de inovação como base para as discussóes sobre renovação institucional voltada ao tema da tecnologia e inovação. As implicaçóes de uma abordagem sistêmica adaptativa para a pesquisa agrícola, com uma visão de inovação em gestão, tiveram o objetivo de apoiar a discussão sobre a concepção do tema de agilidade.

A gestão ágil e o conceito de agilidade foram discutidos como uma abordagem inovadora para os ecossistemas de inovaçáo na agricultura, com o objetivo de enfrentar desafios contemporâneos. Conforme analisado, o emprego do conceito de agilidade, que em resumo está relacionado à habilidade de adaptação, tem apresentado ganhos na melhoria de desempenho das organizaçóes e seria um fator de sobrevivência para ecossistemas de inovação. A revisão procurou demonstrar diferentes níveis em que a agilidade pode ser examinada e desenvolvida, desde os mais estratégicos aos operacionais, que envolveriam características distintas e complementares de adaptação das organizaçôes que compóem o ecossistema.

A Embrapa tem se disponibilizado para ajudar a desenvolver esta linha de pesquisa. A análise da trajetória gerencial da instituição demonstra oportunidades considerando as diferentes unidades da Embrapa, os atores envolvidos, seus diversos níveis de desdobramento de estratégias, os macroprogramas e os portfólios de projetos. Foram apresentados casos de iniciativas de aprimoramento gerencial na instituiçáo, relatados na literatura. Buscou-se chamar atenção para um possível caminho de desenvolvimento, destacando-se as possíveis variáveis que poderiam ser sistematizadas para uma estratégia mais abrangente.

As estratégias e as práticas ágeis identificadas nos levantamentos foram descritas, com destaque para: adaptação de estruturas e instrumentos de gestão nas unidades; ações para impulsionar um processo iterativo; contínuo envolvimento de agentes internos e externos em prol de alinhamento para demandas e soluçôes; dinamismo e alinhamento no desenvolvimento de lideranças; aspectos ambientais; desafios e limitaçóes. São diversas frentes para análise e desenvolvimentos.

Foi possível explorar conceitos complementares voltados a pensar um cenário de próximos passos, em que a instituição seja vista como um ecossistema ágil de inovação. Buscou-se realizar uma análise sobre o potencial da teoria de agilidade na compreensão de desafios e transformaçóes da Embrapa. Previamente, pondera-se que uma priorização para frentes de trabalho ajudaria a observar e endereçar os fatores de preocupação abordados na literatura e nos desafios apontados pelos entrevistados. 
Como oportunidades de pesquisas futuras e aprimoramento do trabalho, estariam o desenvolvimento de planos de implementação e acompanhamento na Embrapa e outras organizaçóes que compóem ou influenciam seu ecossistema. Uma investigação em maior escala possibilitaria o fortalecimento da proposta. Considera-se, por fim, que a medição de agilidade e avaliação de seu impacto nos resultados da pesquisa agrícola, na otimização do orçamento das instituiçôes e na produtividade do setor como um todo pode contribuir com a geração de políticas públicas e diretrizes para a gestão da inovação. Há potencial para transformação dos ecossistemas de inovação, com o objetivo de ajudar o país na corrida global competitiva e nas respostas para a sociedade.

\section{REFERÊNCIAS}

ADNER, R. Match your innovation strategy to your innovation ecosystem. Harvard Business Review, v. 84, n. 4, p. 98-107, 2006.

ALANGE, S.; JACOBSSON, S.; JARNEHAMMAR, A. Some aspects of an analytical framework for studying the diffusion of organizational innovations. Technology Analysis \& Strategic Management, v. 10, n. 1, p. 3-20, 1998.

ALVES, E. A neutralidade da tecnologia. Revista de Política Agrícola, ano 10, n. 4, p. 38-52, out./dez. 2001.

. Embrapa: um caso bem-sucedido de inovação institucional. Revista de Política Agrícola, ano 19, edição especial, p. 65-73, 2010.

. Embrapa: institutional building and technological innovation required for cerrado agriculture. In: HOSONO, A.; DA ROCHA, C. M. C.; HONGO, Y. (Orgs). Development for sustainable agriculture: the Brazilian cerrado. Basingstoke: Palgrave Macmillan, 2015.

ALVES, E.; SOUZA, G. A pesquisa agrícola numa agricultura integrada ao mercado internacional: o caso da Embrapa e do Cerrado. Revista de Política Agrícola, ano 16, n. 2, p. 56-67, abr./jun. 2007.

ALVES, E.; SILVA E SOUZA, G.; ROCHA, D. Lucratividade da agricultura. Revista de Política Agrícola, ano 21, n. 2, p. 45-63, abr./jun. 2012.

ALVES, E. et al. Os três problemas da agricultura e suas soluções. Revista de Política Agrícola. ano 28, n. 3, p. 5-8, jul./set. 2019.

AMARAL, D. et al. Gerenciamento ágil de projetos: aplicação em produtos inovadores. São Paulo: Saraiva. 2011.

ARGYROPOULOU, M.; SODERQUIST, K. E.; IOANNOU, G. Getting out of the European paradox trap: making european research agile and challenge driven. European Management Journal, v. 37, n. 1, p. 1-5, Feb. 2019. 
AYELE, S. et al. Enhancing innovation in livestock value chains through networks: lessons from fodder innovation case studies in developing countries. Science Public Policy, v. 39, n. 3, p. 333-346, June 2012.

BACKLANDER, G. Doing complexity leadership theory: how agile coaches at Spotify practise enabling leadership. Creativity and Innovation Management, v. 28, n. 1. p. 42-60, Jan. 2019.

BATTISTELLA C. et al. Cultivating business model agility through focused capabilities: a multiple case study. Journal of Business Research, v. 73, p. 65-82, Apr. 2017.

BECK, K. et al. Manifesto for agile software development. 2001. Disponível em: <https:// is.gd/G5Pdqf>. Acesso em: 10 fev. 2020.

BENASSI, J. L.; AMARAL, D. C.; FERREIRA, L. D. Towards a conceptual framework for product vision. International Journal of Operations and Production Management, v. 36, n. 2, p. 200-219, 2016.

BIRKINSHAW, J.; HAMEL, G.; MOL, M. J. Management innovation. Academy of Management Review, v. 33, n. 4, p. 825-845, 2008.

BOEHM, B.; TURNER, R. Balancing agility and discipline: a guide for the perplexed. Boston: Addison-Wesley, 2004.

BRASIL. Ministério da Agricultura, Pecuária e Abastecimento. Agrofoco, ano 2, set. 2020. Disponível em: <https://tinyurl.com/y6dlxb98>. Acesso em: 18 set. 2020.

BRESCHI, S.; MALERBA, F. Sectoral innovation systems. In: EDQUIST, C. (Ed.). Systems of innovation: technologies, institutions and organisations. London: Pinter, 1997.

CAISAN - CÂMARA INTERMINISTERIAL DE SEGURANÇA ALIMENTAR E NUTRICIONAL. Estratégia intersetorial para a reduçáo de perdas e desperdício de alimentos no Brasil. Brasília: Caisan, 2018. Disponível em: <https://tinyurl.com/y5qv9s7q>. Acesso em: 10 set. 2020.

CAMPBELL, B. M.; SAYER, J. Integrated natural resource management: linking productivity, the environment and development. Wallingford: Cabi, 2003.

CARAYANNIS, E. G.; CAMPBELL, D. F. J. 'Mode 3' and 'quadruple helix': toward a 21st century fractal innovation ecosystem. International Journal of Technology Management, $v$. 46, n. 3-4, p. 201-234, 2009.

CARLOS, R.; AMARAL, D. C.; CAETANO, M. Framework for continuous agile technology roadmap updating. Innovation \& Management Review, v. 15, n. 3, p. 321-336, 2018.

CARLSSON, B.; JACOBSSON, S. Diversity creation and technological systems: a technology policy perspective. In: EDQUIST, C. (Ed.). Systems of innovation: technologies, institutions and organisations. London: Pinter, 1997. 
CNA - CONFEDERAÇÃO DA AGRICULTURA E PECUÁRIA DO BRASIL; CONSELHO DO AGRO - CONSELHO DAS ENTIDADES DO SETOR AGROPECUÁRIO. O futuro é agro: Plano de Estado (2018-2030). Brasília: CNA; Conselho do Agro, 2018. 139 p. Disponível em <https://tinyurl.com/y43cdtx7>. Acesso em: 1ํo mar. 2020.

COHEN, W. M.; LEVINTHAL, D. A. Absorptive capacity: a new perspective on learning and innovation. Administrative Science Quarterly, v. 35, n. 1, p. 128-152, Mar. 1990.

COHN, M. Agile estimating and planning. New York: Prentice Hall PTR, 2005.

CONFORTO, E. Modelo e ferramenta para avaliaçáo da agilidade no gerenciamento de projetos. 2013. 376f. Tese (Doutorado) - Programa de Pós-Graduação de Engenharia de Produção, Escola de Engenharia de São Carlos, Universidade de São Paulo, São Paulo, 2013.

CONFORTO, E.; AMARAL, D. C. Agile project management and stage-gate model: a hybrid framework for technology-based companies. Journal of Engineering and Technology Management, v. 40, p. 1-14, Apr./June 2016.

CONFORTO, E.; AMARAL, D. C.; SILVA, S. L. Roteiro para revisão bibliográfica sistemática: aplicação no desenvolvimento de produtos e gerenciamento de projetos. In: CONGRESSO BRASILEIRO DE INOVAÇÃO E GESTÃO DO DESENVOLVIMENTO DE PRODUTO, 8., Porto Alegre, Rio Grande do Sul. Anais... Porto Alegre: CBGDP, 2011.

CONFORTO, E. C. et al. Modelos híbridos unindo complexidade, agilidade e inovação. Revista Mundo PM, v. 70, n. 2, p. 10-57, 2015.

CONFORTO, E. et al. The agility construct on project management theory. International Journal of Project Management, v. 34, n. 4, p. 660-674, May 2016.

COOKE, P. Regional innovation systems: an evolutionary approach. In: BARACZYK, H.; COOKE, P.; HEIDENRIECH, R. (Eds.). Regional innovation systems. London: London University Press, 1996.

COOPER, R. G. What's next? After stage-gate. Research Technology Management, v. 57, p. 20-31, 2014. Jan. 2016.

Agile-stage-gate hybrids. Research Technology Management, v. 59, n. 1, p. 21-29,

COOPER, R. G.; EDGETT, S. Product innovation and technology strategy. Ancaster: Product and Development Institute Inc., 2009.

CRESTANA, S.; FIGUEIREDO, R. Contribuições tecnológicas da Embrapa para a agricultura tropical: conquistas, futuros desafios e oportunidades. In: VAZ, C. M.; HERMANN JÚNIOR, S. P.; MEIO, W. L. B. (Eds.). Visáo tecnológica e social para o agronegócio: ciclo de colóquios da Embrapa Instrumentação Agropecuária. São Carlos: Embrapa Instrumentação Agropecuária, 2008. 215p. 
CRESTANA, S.; FRAGALLE, E. P. A trilha da quinta potência: um primeiro ensaio sobre ciência e inovação, agricultura e instrumentação agropecuária brasileiras. Revista Eixo, Brasília, v.1, n. 1, p. 7-19. 2012.

CRESTANA, S.; MAGALHÂES, B. A cooperação técnica na política externa do Brasil em agricultura: o papel da Embrapa. In: Cooperaçáo técnica na política externa: realizaçóes e desafios. Brasília: Funag; ABC, 2007. 15p.

CRESTANA, S.; CONTINI, E.; RODRIGUES, R. Tecnologia e inovação no agro. In: RODRIGUES, R. (Org.). Agro é paz: análises e propostas para o Brasil alimentar o mundo. Piracicaba: Esalq, 2018.

DENNING, S. Why only the agile will survive. Forbes, 19 abr. 2020. Disponível em: <https:// tinyurl.com/yy8ahydz>. Acesso em: 20 abr. 2020.

DHANARAJ, C.; PARKHE, A. Orchestrating innovation networks. Academy of Management Review, v. 31, n. 3, p. 659-669, 2006.

DINGSØYR, T.; MOE, N. Towards principles of large-scale agile development. In: DINGSØYR, T. et al. (Eds.). Agile methods: large-scale development, refactoring, testing, and estimation. Springer International Publishing, 2014. p. 1-8. (Lecture Notes in Business Information Processing, v. 199).

DOUTHWAITE, B.; HOFFECKER, E. Towards a complexity-aware theory of change for participatory research programs working within agricultural innovation systems. Agricultural Systems, v. 155, p. 88-102, July 2017.

DUPONT, L. Agile innovation: creating value in uncertain environments. Journal of Innovation Economics \& Management, n. 28, p. 1-5, 2019.

DYBA, T.; DINGSOYR, T. What do we know about agile software development? IEEE Software, v. 26, n. 5, p. 0-3, 2009.

EDQUIST, C.; JOHNSON, B. Institutions and organizations in systems of innovation. In: EDQUIST, C. (Ed.). Systems of innovation: technologies, institutions and organisations. London: Pinter, 1997.

ELO, S.; KYNGAS, H. The qualitative content analysis process. Journal of Advanced Nursing, v. 62, n. 1, p. 107-115, May 2007.

EMBRAPA - EMPRESA BRASILEIRA DE PESQUISA AGROPECUÁRIA. Política de inovaçáo da Embrapa. Brasília: Embrapa, 2018. Disponível em: <https://is.gd/pv4W7x>. Acesso em: 16 abr. 2019.

ESPOSTI, R. Public agricultural R\&D design and technological spill-ins: a dynamic model. Research Policy, v. 31, n. 5, p. 693-717, July 2002. 
FAGERBERG, J.; LUNDVALL, B.-A.; SRHOLEC, M. Global value chains, national innovation systems and economic development. The European Journal of Development Research, v. 30, p. 533-556, 2018.

FECHER, F. et al. Innovation labs from a participants' perspective. Journal of Business Research. v. 110, p. 567-576, Mar. 2020.

FITZGERALD, B. et al. Scaling agile methods to regulated environments: an industry case study. In: PROCEEDINGS OF INTERNATIONAL CONFERENCE ON SOFTWARE ENGINEERING, 35., San Francisco, California. Anais... IEEE Publications, 2013. p. 863-872.

FLORICEL, S.; PIPERCA, S.; TEE, R. Strategies for managing the structural and dynamic consequences of project complexity. Complexity, 13 May 2018.

FREEMAN, C. The national system of innovation in historical perspective. Cambridge Journal of Economics, v. 19, n. 1, p. 5-24, 1995.

GASQUES, J. G. Sources of growth in Brazilian agriculture: total factor productivity. EuroChoices, v. 16, n. 1, p. 24-25, Apr. 2017.

GAWER, A.; CUSUMANO, M. A. How companies become platform leaders. MIT Sloan Management Review, v. 49, n. 2, 2008.

GIL, A. Como elaborar projetos de pesquisa. Atlas: São Paulo, 1999.

GOLDMAN, S. L.; NAGEL, R. N.; PREISS, K. Agile competitors and virtual organizations: strategies for enriching the customer. New York: Van Nostrand Reinhold, 1995.

GOMES, L. A. V. et al. Unpacking the innovation ecosystem construct: evolution, gaps and trends. Technological Forecasting \& Social Change, v. 136, p. 30-48, Nov. 2018.

GRANSTRAND, O.; HOLGERSSON, M. Innovation ecosystems: a conceptual review and a new definition. Technovation, v. 90-91, p. 1-12, 2020.

GROENEWEGEN, J.; STEEN, M. The evolution of national innovation systems. Journal of Economic Issues, v. 40, n. 2, p. 277-285, 2006.

GUILLÉN, M. F. Models of management: work, authority, and organization in a comparative perspective. Chicago: University of Chicago Press, 1994.

GUNASEKARAN, A. Agile manufacturing: a framework for research and development. International Journal of Production Economics, v. 62, n. 1-2, p. 87-105, May 1999.

HIGHSMITH, J. Agile project management: creating innovative products. Boston: Addison-Wesley, 2004.

HOFFECKER, E. Understanding innovation ecosystems: a framework for joint analysis and action. Cambridge: MIT D-Lab, 2019. 
IANSITI, M.; LEVIEN, R. Strategy as ecology. Harvard Business Review, v. 82, n. 3, p. 6878, Mar. 2004.

IANSITI, M.; EUCHNER, J. Competing in ecosystems. Research-Technology Management, v. 61, n. 2, p. 10-16, 2018.

JING, Z.; XIONG-JIAN, L. Business ecosystem strategies of mobile network operators in the 3G era: the case of China mobile. Telecommunications Policy, v. 35, n. 2, p. 156-171, 2011.

KATZY, B. R.; CROWSTON, K. Competency rallying for technical innovation: the case of the virtuelle fabrik. Technovation, v. 28, n. 10, p. 679-692, Oct. 2008.

KLERKX, L.; ARTS, N.; LEEUWIS, C. Adaptive management in agricultural innovation systems: the interactions between innovation networks and their environment. Agricultural Systems, v. 103, n. 6, p. 390-400, July 2010.

KLERKX, L.; MIERLO, B. V.; LEEUWIS, C. Evolution of systems approaches to agricultural innovation: concepts, analysis and interventions. In: DANHEFER, I.; GIBBON, D.; DEDIEU, B. (Eds.). Farming systems research into the 21st century: the new dynamic. Amsterdam: Springer, 2012. p. 457-483.

KRAMER, H. The philosophical foundations of management rediscovered. Management International Review, v. 15, n. 2-3, p. 47-55, 1975.

KRSTIC, M.; SKORUP, A.; LAPCEVIC, G. Trends in agile innovation management. International Review, v. 3-4, p. 58-70, 2018.

KUIVALAINEN, J.; KUNTTU, I.; KOHTAMAKI, M. Agile product development practices for coping with a learning paradox in $\mathrm{R} \& \mathrm{D}$ offshore units. Technology Innovation Management Review, v. 10, n. 3, p. 69-77, Mar. 2020.

LEMINEN, S. Living labs as open innovation networks: networks, roles and innovation outcomes. Helsinki: Aalto University, 2015.

LEWIS, M. W. Exploring paradox: toward a more comprehensive guide. The Academy of Management Review, v. 25, n. 4, p. 760-776, 2000.

LUNDVALL, B.-A. et al. National systems of production, innovation and competence building. Research Policy, v. 31, n. 2, p. 213-231, 2002.

National innovation systems: analytical concept and development tool. Journal Industry and Innovation, v. 14, n. 1, p. 95-119, 2007.

MASKELL, P.; MALMBERG, A. Localised learning and industrial competitiveness. Cambridge Journal of Economics. v. 23, n. 2, p. 167-186, 1999.

MERGEL, I.; GONG, Y.; BERTOT, J. Agile government: systematic literature review and future research. Government Information Quarterly, v. 35, n. 2, 291-298, Apr. 2018. 
MOORE, J. F. Predators and prey: a new ecology of competition. Harvard Business Review, v. 71, n. 3, p. 75-86, 1993.

NAGEL, R.; DOVE, R. 21st century manufacturing: enterprise strategy. Bethlehem: Iacocca Institute/Lehigh University, 1991.

NAMBISAN, S.; BARON, R. A. Entrepreneurship in innovation ecosystems: Entrepreneurs' self-regulatory processes and their implications for new venture success. Enterprise Theory Pract, v. 37, n. 5, p. 1071-1097, 2013.

NASCIMENTO, P. A trajetória da cooperação científica internacional da Embrapa: do emparelhamento tecnológico (catching-up) com a revolução verde à liderança tecnológica na agricultura tropical. 2016. 164f. Tese (Doutorado) - Universidade Federal do Rio de Janeiro, Instituto de Economia, Programa de Pós-Graduação em Políticas Públicas, Estratégias e Desenvolvimento, Rio de Janeiro, 2016.

NELSON, R. As fontes do crescimento econômico. Campinas: Editora da Unicamp, 2006.

OCDE - ORGANIZAÇÃO PARA A COOPERAÇÃO E O DESENVOLVIMENTO ECONÔMICO; FAO - ORGANIZAÇÃO DAS NAÇÔES UNIDAS PARA A ALIMENTAÇÃO E A AGRICULTURA. OECD-FAO Agricultural Outlook 2018-2027. Roma: OECD Publishing; Paris: FAO, 2018. Disponível em <https://doi.org/10.1787/agr_outlook-2018-en>. Acesso em: 6 jul. 2020.

OECD - ORGANISATION FOR ECONOMIC CO-OPERATION AND DEVELOPMEN. Achieving public sector agility at times of fiscal consolidation: OECD public governance reviews. Paris: OECD Publishing, 2015.

OJHA, H. R.; HALL, A. Adaptive collaborative approaches in natural resource governance: rethinking participation, learning and innovation. Chicago: Routledge, 2013.

ONU - ORGANIZAÇÃO DAS NAÇŌES UNIDAS. Agenda 2030 para o Desenvolvimento Sustentável. Nova York: ONU, 2015. Disponível em: <https://nacoesunidas.org/pos2015/>. Acesso em: 10 jul. 2020.

PAASIVAARA, M. et al. Integrating global sites into the lean and agile transformation at Ericsson. In: INTERNATIONAL CONFERENCE ON GLOBAL SOFTWARE ENGINEERING, 8., 2013, Bari, Italy. Annals... Bari: IEEE, 2013.

Large-scale agile transformation at Ericsson: a case study. Empirical Software Engineering, v. 23, n. 3, p. 2550-2596, Oct. 2018.

PARENTE, R. et al. Public sector organizations and agricultural catch-up dilemma in emerging markets: the orchestrating role of Embrapa in Brazil. Journal of International Business Studies, 21 Apr. 2020. 
PEIXOTO, M.; PINTO, H. S. Desperdício de alimentos: questões socioambientais, econômicas e regulatórias. Brasília: Núcleo de Estudos e Pesquisas/Conleg/Senado, fev. 2016. (Boletim Legislativo, n. 41). Disponível em: <www.senado.leg.br/estudos>. Acesso em: 6 out. 2020.

PÉREZ-BUSTAMANTE, G. Knowledge management in agile innovative organisations. Journal of Knowledge Management, v. 3, n. 1, p. 6-17, 1999.

REEVES, M. et al. Transforming for growth: an evidence based guide. Boston: BCG Henderson Institute, 2020.

REYNOLDS, E. B.; SCHNEIDER, B. R.; ZYLBERBERG, E. Innovation in Brazil: advancing development in the 21st century. London: Routledge, 2019.

RIGBY, D.; SUTHERLAND, J.; TAKEUCHI, H. Embracing agile. Harvard Business Review, 2016.

ROHUNEN, A.; RODRIGUEZ, P.; KUVAJA, P. Approaches to agile adoption in large settings: a comparison of the results from a literature analysis and an industrial inventory. Profes LNCS, v. 6156, p 77-91, 2010.

RONSOM, S.; AMARAL, D. Avaliando o potencial de aplicação do conceito de agilidade na gestão de tecnologia em ICTs: o caso Embrapii. In: CONGRESSO BRASILEIRO DE INOVAÇÃO E GESTÁO DO DESENVOLVIMENTO DE PRODUTO, 12., 2019, Brasília, Distrito Federal. Anais... Brasília, 2019.

ROSENBERG, N. Why do firms do basic research (with their own money)? Research Policy, v. 19, n. 2, p. 165-174, Apr. 1990.

RUBENS, N. et al. A network analysis of investment firms as resource routers in Chinese innovation ecosystem. Journal of Software, v. 6, n. 9, p. 1737-1745, 2011.

SAN CRISTÓBAL, J.-R. et al. Complexity and project management: challenges, opportunities, and future research. Complexity, v. 2019, p. 1-2, 2019.

SCHAFFER, R. H. All management is change management. Harvard Business Review, 2017.

SCHUT, M. et al. Innovation platforms: experiences with their institutional embedding in agricultural research for development. Experimental Agriculture, v. 52, n. 4, p. 537-561, 2016.

SCHWABER, K. Agile project management with Scrum. Microsoft Press: Washington, 2004.

SHARIFI, H.; ZHANG, Z. Agile manufacturing in practice: application of a methodology. International Journal of Operations \& Production Management, v. 21, n. 5-6, p. 772-794, 2001.

SILVA, H. L. Avaliaçáo das práticas de qualidade assegurada em modelos híbridos de gestão de projetos aplicados em ambientes regulados. 2019. 127f. Dissertação (Mestrado) - Escola de Engenharia de São Carlos, Universidade de São Paulo, São Carlos, 2019. 
SILVA, S. S. et al. Analysis of the process of technology transfer in public research institutions: the Embrapa agrobiology case. Innovation \& Management Review, v. 16, n. 4, p. 375-390, 2019.

SULL, D. Competing through organizational agility. McKinsey Quartely, 1st Dec. 2009. Disponível em: <https://tinyurl.com/yy5gvnss>. Acesso em: 20 fev. 2020.

SUTHERLAND, J.; SCHWABER, K. The Scrum Guide. 2017. p. 1-37. Disponível em: <https://tinyurl.com/y9q2h23k>. Acesso em: 30 maio 2020.

SWEETMAN, R.; CONBOY, K. Portfolios of agile projects: a complex adaptive systems' agent perspective. Project Management Journal, v. 49, n. 6, p. 18-38, 2018.

TEECE, D. J. Explicating dynamic capabilities: the nature and microfoundations of (sustainable) enterprise performance. Strategic Management Journal, v. 28, n. 13, p. 1319-1350, 2007.

TEECE, D. J.; PETERAF, M.; LEIH, S. Dynamic capabilities and organizational agility: risk, uncertainty, and strategy in the innovation economy. California Management Review, v. 58, n. 4, p. 13-35, 2016.

UN - UNITED NATIONS. World population projected to reach 9.8 billion in 2050, and 11.2 billion in 2100. New York: UN, 2017. Disponível em: <https://tinyurl.com/y6cftbtu>. Acesso em: 15 set. 2020.

VIDMAR, M. Agile space living lab: the emergence of a new high-tech innovation paradigm. Space Policy. v. 9, n. 101324, Aug. 2019.

VIEIRA FILHO, J. E. R. Coronavírus e os impactos no setor agropecuário brasileiro. Revista de Política Agrícola, v. 29, n. 2, p. 3-7, abr./maio/ jun. 2020.

VIEIRA FILHO, J. E. R.; FISHLOW, A. Agricultura e indústria no Brasil: inovação e competitividade. Brasília: Ipea, 2017.

VIEIRA FILHO, J. E. R.; SILVEIRA, J. M. F. J. Modelo evolucionário de aprendizado agrícola. Revista Brasileira de Inovação, v. 10, n. 2, p. 265-300, 2011.

VIEIRA FILHO, J. E. R.; GASQUES, J. G.; RONSOM, S. Inovação e expansão agropecuária brasileira. In: VIEIRA FILHO, J. E. R.; GASQUES, J. G. (Orgs.). Uma jornada pelos contrastes do Brasil: 100 anos de Censo Agropecuário. Brasília: Ipea, 2020. cap. 8.

VISHNEVSKIY, K.; KARASEV, O.; MEISSNER, D. Integrated roadmaps and corporate foresight as tools of innovation management: the case of Russian companies. Technological Forecasting and Social Change, v. 90, part B, p. 433-443, Jan. 2015.

WEIBLEN, T.; CHESBROUGH, H. W. Engaging with startups to enhance corporate innovation. California Management Review, v. 57, n. 2, p. 66-90, 2015.

WIGBOLDUS, S. et al. Systemic perspectives on scaling agricultural innovations: a review. Agronomy for Sustainable Development, v. 36, n. 3, p. 1-20, Sept. 2016. 
WILSON, K.; DOZ, Y. Agile innovation: a footprint balancing distance and immersion. California Management Review, v. 53, n. 2, p. 6-26, 2011.

ZAHRA, S. A.; NAMBISAN, S. Entrepreneurship and strategic thinking in business ecosystems. Business Horizons, v. 55, n. 3, p. 219-229, 2012.

ZARO, M. Desperdício de alimentos: velhos hábitos, novos desafios. 2. ed. Caxias do Sul: Educs, 2018. 

Ipea - Instituto de Pesquisa Econômica Aplicada

\title{
EDITORIAL
}

\section{Chefe do Editorial}

Reginaldo da Silva Domingos

\section{Assistentes da Chefia}

Rafael Augusto Ferreira Cardoso

Samuel Elias de Souza

\section{Supervisão}

Camilla de Miranda Mariath Gomes

Everson da Silva Moura

\section{Editoração}

Aeromilson Trajano de Mesquita

Anderson Silva Reis

Cristiano Ferreira de Araújo

Danilo Leite de Macedo Tavares

Jeovah Herculano Szervinsk Junior

Leonardo Hideki Higa

\section{Capa}

Danielle de Oliveira Ayres

Flaviane Dias de Sant'ana

\section{Projeto Gráfico}

Renato Rodrigues Bueno

The manuscripts in languages other than Portuguese published herein have not been proofread.

\author{
Livraria Ipea \\ SBS - Quadra 1 - Bloco J - Ed. BNDES, Térreo \\ 70076-900 - Brasília - DF \\ Tel.: (61) 2026-5336 \\ Correio eletrônico: livraria@ipea.gov.br
}



Composto em adobe garamond pro 12/16 (texto) Frutiger 67 bold condensed (títulos, gráficos e tabelas) Brasília-DF 



\section{Missão do Ipea}

Aprimorar as políticas públicas essenciais ao desenvolvimento brasileiro por meio da produção e disseminação de conhecimentos e da assessoria ao Estado nas suas decisões estratégicas.

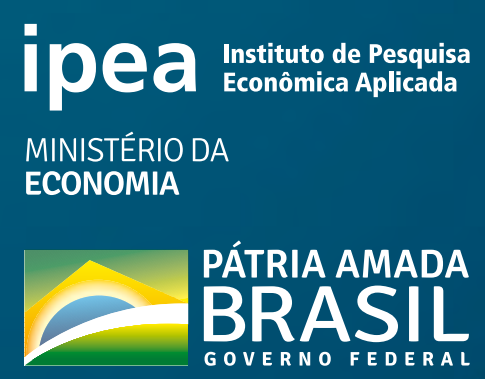

